\title{
Demyelination, Astrogliosis, and Accumulation of Ubiquitinated Proteins, Hallmarks of CNS Disease in hsf1-Deficient Mice
}

\author{
Sachiko Homma, ${ }^{1 \star}$ Xiongjie Jin, ${ }^{1 *}$ Guanghu Wang, ${ }^{1 *}$ Naxin Tu, ${ }^{1 *}$ Jinna Min, ${ }^{1}$ Nathan Yanasak, ${ }^{2}$ and Nahid F. Mivechi ${ }^{1,2}$ \\ ${ }^{1}$ Center for Molecular Chaperone/Radiobiology and Cancer Virology, ${ }^{2}$ Department of Radiology, Medical College of Georgia, Augusta, Georgia 30912
}

The heat shock transcription factors (Hsfs) are responsible for the heat shock response, an evolutionarily conserved process for clearance of damaged and aggregated proteins. In organisms such as Caenorhabditis elegans, which contain a single Hsf, reduction in the level of Hsf is associated with the appearance of age-related phenotypes and increased accumulation of protein aggregates. Mammalian cells express three $h s f s(h s f 1, h s f 2, h s f 4)$ and their role in CNS homeostasis remains unclear. In this study, we examined the effects of deletion of single or multiple $h s f$ genes in the CNS using mutant mice. Our results show that $h s f 1^{-1-}$ mice display progressive myelin loss that accompanies severe astrogliosis and this is exacerbated in the absence of either the $h s f 2$ or $h s f 4$ gene. Magnetic resonance imaging and behavioral studies indicate reduction in the white matter tracts of the corpus callosum, and deficiencies in motor activity, respectively, in aged $h s f 1^{-1-}$ mice. Concomitantly, $h s f 1^{-1-}$ aged CNS exhibit increased activated microglia and apoptotic cells that are mainly positive for GFAP, an astrocyte-specific marker. Studies based on the expression of short-lived ubiquitinated green fluorescent protein (GFPu) in living $h s f 1^{-l-}$ cells indicate that they exhibit reduced ability to degrade ubiquitinated proteins, accumulate short-lived GFPu, and accumulate aggregates of the Huntington's model of GFP containing trinucleotide repeats (Q103-GFP). Likewise, $h s f 1^{-1-}$ brain and astrocytes exhibit higher than wild-type levels of ubiquitinated proteins, increased levels of protein oxidation, and increased sensitivity to oxidative stress. These studies indicate a critical role for mammalian $h s f$ genes, but specifically $h s f l$, in the quality control mechanisms and maintenance of CNS homeostasis during the organism's lifetime.

Key words: heat shock factors; myelin; astrogliosis; neurodegeneration; demyelination; knock-out mice

\section{Introduction}

Heat shock proteins (Hsps) or molecular chaperones play an important role in protein folding and degradation and, as such, play a central role in the pathophysiology of several of the neurodegenerative diseases (Soti and Csermely, 2002; Barral et al., 2004; Muchowski and Wacker, 2005). Inducibility of Hsps by environmental insults (e.g., heat shock or oxidative stress) is in part regulated by heat shock factors (Hsfs) (Wu, 1995; Morimoto, 1998). Hsfs bind to heat shock elements present on the promoters of Hsps and other genes, but the mechanisms responsible for Hsf transcriptional activation are diverse (Wu, 1995;

Received Aug. 7, 2006; revised May 28, 2007; accepted June 6, 2007.

This work was supported by National Institutes of Health Grants CA62130 and GM070451. We thank Dr. Nico Dantuma for providing plasmids encoding Ub-R-GFP and Ub-M-GFP. We also thank our laboratory members Monica Meyer for technical assistance and Dr. Yanzhong Hu for help with culturing neurons. We sincerely appreciate the helpful suggestions of Drs. Zheng Dong, Makoto Yanagisawa, and Dasgupta Somsankar at Medical College of Georgia.

*S.H., X.J., G.W., and N.T. contributed equally to this work.

Correspondence should be addressed to Dr. Nahid F. Mivechi, Medical College of Georgia, 1410 Laney Walker Boulevard, CN-3141A, Augusta, GA 30912. E-mail: nmivechi@mcg.edu.

G. Wang's present address: Institute of Molecular Medicine and Genetics, Medical College of Georgia, Augusta, GA 30912.

J. Min's present address: Department of Cell and Developmental Biology, University of North Carolina at Chapel Hill, Chapel Hill, NC 27599 .

D0I:10.1523/JNEUROSCI.0006-07.2007

Copyright $\odot 2007$ Society for Neuroscience $\quad$ 0270-6474/07/277974-13\$15.00/0
Morimoto, 1998). In yeast, Drosophila, and Caenorhabditis elegans, there is a single hsf gene. Hsf in yeast is an essential gene, whereas in Drosophila, Hsf deficiency leads to defects during early development and lack of stress response (Wu, 1995; Morimoto, 1998). Reduction in the level of Hsf in C. elegans leads to reduced life span and increased age-related phenotypes, such as accumulation of protein aggregates, suggesting a critical role for Hsf during aging (Hsu et al., 2003). In mammals, there are three Hsfs (Hsf1, -2, and -4), with Hsf1 being the critical factor whose activation is dependent on the environmental stresses such as elevated temperature, oxidative stress, or conditions that increase protein misfolding in cells (Wu, 1995; Morimoto, 1998). Hsf2 and Hsf4 participate in similar processes through activation of perhaps the same target genes, but the modes of their activation are less well defined. Hsf2 activity has been shown to be required during radial glial migration and spermatogenesis (G. Wang et al., 2003, 2004; Chang et al., 2006). Hsf4 activity has been demonstrated during lens fiber cell differentiation (Fujimoto et al., 2004; Min et al., 2004). On the basis of recent studies using mice deficient in individual Hsfs, there is now clear evidence that all Hsfs play an important role during development and differentiation-related processes (Xiao et al., 1999; G. Wang et al., 2003, 2004; Fujimoto et al., 2004; Min et al., 2004). $h s f 1^{-l-}$ cells are susceptible to cytotoxic effects of heat shock because these cells undergo increased apoptosis when exposed to multiple heat 
exposures (McMillan et al., 1998; Xiao et al., 1999; Zhang et al., 2002; Santos and Saraiva, 2004; G. Wang et al., 2004; Takaki et al., 2006). This lack of adaptive response to heat shock is attributable to the absence of stress-inducible Hsps (Zhang et al., 2002).

Process of aging in the CNS is associated with variety of cellular changes. These cellular modifications implicate the oxidative stress and reduction in the ubiquitin (Ub) proteasome function as critical factors leading to protein aggregation and increased cell death in the aged CNS (D. S. Wang et al., 2004; Mariani et al., 2005). Age-related neurodegenerative diseases such as Alzheimer's disease and trinucleotide repeat diseases (such as Huntington's disease) exhibit increased oxidative damage in different compartments of the brain and they are associated with neuronal cells harboring inclusion bodies, resulting in neuronal loss (Price et al., 1998; Butterfield et al., 2001). The inclusion bodies contain protein aggregates that are immunoreactive for $19 S$ and $26 S$ proteasomes, ubiquitin, and molecular chaperones, suggesting that the Ub-proteasome system and molecular chaperones are involved in the degradation of such protein aggregates (Price et al., 1998; Goldberg, 2003; Muchowski and Wacker, 2005). Molecular chaperones or Hsps have been implicated to protect cells against oxidative damage and they affect protein aggregation of diseased proteins such as polyQ-containing proteins or $\mathrm{A} \beta$ peptide (Goldberg, 2003; Barral et al., 2004). Overexpression of specific Hsps has been shown to reduce neuronal toxicity [e.g., mice overexpressing Ataxin $182 \mathrm{Q}$ crossed with an Hsp70-expressing transgenic line improves the neuropathological phenotypes of Ataxin 1 Q82 mice (Cummings et al., 1998)]. In addition, genetic screens in Drosophila melanogaster and C. elegans models of polyglutamine aggregation have identified Hsp40 and Hsp70 as suppressors of polyQ-related neurotoxicity (Kazemi-Esfarjani and Benzer, 2000; Auluck et al., 2002; Goldberg, 2003). Reduction in myelin is also a common occurrence of aging and is observed in age-related neurodegenerative diseases such as Alzheimer's disease (D. S. Wang et al., 2004). In elderly brains, ubiquitin immunoreactivity and degenerative myelin is detected, perhaps as a result of an age-related increase in protein damage and delayed rate of remyelination because of the decline in oligodendrocyte progenitor recruitment and their differentiation to mature oligodendrocytes (Franklin et al., 2002; D. S. Wang et al., 2004). In addition to oligodendrocytes, both neurons and glia are intimately involved in myelin biogenesis. These cells release factors such as IGF1 (insulin-like growth factor), FGF2 (fibroblast growth factor), PDGF (platelet-derived growth factor), and CNTF (ciliary neurotrophic factor) that control cell growth and survival of oligodendrocytes (Simons and Trajkovic, 2006). Electrical stimulation leads to secretion of promyelinating factors such as leukemia inhibitory factor from astrocytes and adenosine from neurons changing the expression level of adhesion molecules of axonal cell (Simons and Trajkovic, 2006). Therefore, balance of factors released by cells and proper cellular cofactors are necessary for appropriate production and maintenance of CNS during the organism's lifetime.

In this study, we analyzed the requirement of Hsfl and other two Hsfs in the CNS homeostasis. We show that Hsf1 is an essential Hsf that helps to retain some of the features of normal aging brain. As such, $h s f 1^{-1-}$ mice exhibit accelerated demyelination and astrogliosis as well as accumulation of ubiquitinated proteins, and increased protein oxidation, suggesting that the reduction in expression and activity of Hsfl can accelerate agingrelated brain pathology.

\section{Materials and Methods}

Generation of mice deficient in hsf genes. The generation of $h s f 1^{-1-}$, $h s f 2^{-l-}$, or $h s f 4^{-1-}$ mice have been reported previously (Zhang et al., 2002; G. Wang et al., 2003, 2004; Min et al., 2004). Double- and triplemutant mice were generated by crossing $h s f 1^{-1-}$ mice with $h s f 2$ - or hsf4deficient mice followed by intercrosses taking into consideration that $h s f 1^{-1-}$ female mice are infertile, and hsflhsf2-deficient male and female mice are infertile. The genetic background of all of the mouse lines was $(129 \mathrm{~Sv} / \mathrm{Ev}-\mathrm{C} 57 \mathrm{BL} / 6) \mathrm{F}_{2}$, as a result of the partial embryonic lethality observed in $h s f 1^{-1-}$ mice in the pure genetic background. All procedures involving mice were conducted using the Institutional Animal Use and Care Committee with approved protocols.

Genotype analysis. Genotyping of $h s f 1-, h s f 2-$, and $h s f 4$-deficient mice was performed by PCR. For detection of wild-type $h s f 1$, PCR was performed with primer 1, 5'-GAGATGACCAGAATGCTGTGGGTG, and primer 2, 5'-GCAAGCATAGCATCCTGAAAGAG (annealing to intron 1 and exon 1 , respectively). For $h s f 1^{-1-}$ mice, primer $1,5^{\prime}$-ATACACGTGGCTTTTGGCCGCAGA, and primer 2, 5' -ACTGGCCGAAGCCGCTTGGAATAA (annealing to the IRES sequence) were used. The expected PCR products for wild-type and targeted $h s f 1$ loci are fragments of 420 and $285 \mathrm{bp}$, respectively. For detection of the $h s f 2^{-/-}$genotype, multiplex PCR was performed with common primer 1, 5'-GTGGTGTGCGTTCCCCGGAG, primer 2, 5'-TGACTCCAGGTGATGAACTC (annealing to $h s f 2$ coding sequence), and primer 3 (annealing to the EGFP gene, $5^{\prime}$-CTTCGGGCATGGCGGACTTG). The expected PCR products for wild-type and targeted $h s f 2$ loci are fragments of 200 and $406 \mathrm{bp}$, respectively. For detection of $h s f 4^{-1-}$ mice, we used the following: primer $1,5^{\prime}$ GCAAACGCAGCACTTTCGCG annealing to the $h s f 4$ promoter region; primer 2, 5'-CGGATCTTGAAGTTCACCTTGAT annealing to the EGFP gene; and primer 3,5'-TGGACAGGGGTGTTCACGACA binding to the $h s f 4$ allele on the distal arm. The expected PCR products for wild-type and targeted $h s f 4$ loci are fragments of 260 and $600 \mathrm{bp}$, respectively (Zhang et al., 2002; G. Wang et al., 2003, 2004; Min et al., 2004).

Transient transfection assays. Transient transfection assays were performed using Mirus Trans IT-Lt1 (Mirus, Madison, WI). Transfected DNA mixes included 4-8 $\mu \mathrm{g}$ of expression plasmid DNA and, when required, empty plasmid DNA added to a total of $8 \mu \mathrm{g}$. The DNA mixes were added to $5 \times 10^{5}$ cells. The transfection efficiency varied between 60 and $70 \%$ in all experiments, as determined by immunofluorescence analysis (Hu and Mivechi, 2006; Tu et al., 2006).

Flow cytometric analyses. Cells were rinsed twice with PBS and resuspended in $500 \mu \mathrm{l}$ of PBS followed by the addition of $5 \mathrm{ml}$ of methanol. The mixture was incubated for at least $2 \mathrm{~h}$ at $4^{\circ} \mathrm{C}$. Cells were rinsed with PBS and resuspended in $400 \mu \mathrm{l}$ of PBS containing $20 \mu \mathrm{l}$ propidium iodide $(1 \mathrm{mg} / \mathrm{ml})$ and $2 \mu \mathrm{l}$ of RNase $(50 \mathrm{mg} / \mathrm{ml})$. After $30 \mathrm{~min}$ of incubation at $25^{\circ} \mathrm{C}$, flow cytometric analyses were performed using CellQuest Pro with luminescence spectrophotometer (excitation at $480 \mathrm{~nm}$ and emission at $510 \mathrm{~nm}$ ) (Tu et al., 2006).

Immunofluorescence, histology, immunohistochemistry, terminal deoxynucleotidyl transferase-mediated biotinylated UTP nick end labeling, and electron microscopy. For immunofluorescence analyses of astrocytes and neurons, cells were fixed in $4 \%$ paraformaldehyde (PFA), incubated with primary antibodies to glial fibrillary acidic protein (GFAP) (N1506; 1:400; DakoCytomation, Carpinteria, CA), neuronal nuclei (NeuN) (MAB377; 1:250; Chemicon International, Temecula, CA), or ubiquitin (sc-8017; 1:250; Santa Cruz Biotechnology, Santa Cruz, CA) for $1 \mathrm{~h}$ at $25^{\circ} \mathrm{C}$, and then with fluorescent-labeled secondary antibody. Sections were stained with 4,6-diamidino-2-phenylindole (DAPI) before analyses. For histological analyses, tissues were either frozen in OCT or were fixed in 4\% PFA in PBS, embedded in paraffin, sectioned at $10 \mu \mathrm{m}$, and stained with hematoxylin and eosin and subjected to gross and microscopic pathologic analysis. Immunohistochemistry was performed by incubating fixed tissue sections with primary antibody against GFAP (N1506; 1:400; DakoCytomation), O4 (1:250; gift from Dr. P. Fredman, Goteborg, Sweden), myelin basic protein (MBP) (MAB386; 1:500; Chemicon International), MAC3 (14-5989; 1:250; eBioscience, San Diego, CA), NG2 (catalog \#AB5320; 1:250; Chemicon International), CC1 (anti-APC) (Ab-7; clone CC-1; 1:50; Calbiochem, La Jolla, CA), or 
5-bromo-2'-deoxyuridine (BrdU) (DakoCytomation) at $4^{\circ} \mathrm{C}$ overnight. Sections were incubated with fluorescent or alkaline phosphatase (AP)conjugated secondary antibody. In the case of AP, the antigen-antibody complexes were developed with NBT (nitroblue tetrazolium chloride)/ BCIP (5-bromo-4-chloro-3-indolyl phosphate, toluidine salt) in $67 \%$ DMSO (v/v) (Roche Applied Science, Indianapolis, IN). For the quantitation of the immunopositive cells in the tissue sections, number of immunopositive cell bodies was counted by an observer blinded to genotype and treatment using a $20 \times$ objective containing an optical grid. Unbiased stereological cell counts were obtained using a computerassisted image analysis system and Zeiss (Oberkochen, Germany) Axiovision 4.4 image analysis software, including Axiovision Interactive Measurement Module. The counting frame was placed over the counting area, and then systematically moved across the tissue section until the entire area was covered. The tissue area was measured using same system and cell number was standardized per unit area (square millimeter). For terminal deoxynucleotidyl transferase-mediated biotinylated UTP nick end labeling (TUNEL) assays, we used ApopTag Red In Situ Apoptosis Detection kit (Chemicon) that stains cleaved DNA and chromatin condensation associated with apoptosis. Tissue sections were first stained to detect apoptotic cells, and then immunostained with the indicated intracellular markers. For electron microscopy, tissues were fixed in $2.5 \%$ glutaraldehyde for $24 \mathrm{~h}$ and treated with osmification solution $(2 \%$ $\mathrm{OsO}_{4}$ ) for $24 \mathrm{~h}$. After standard dehydration, tissues were embedded, sectioned, and subjected to electron microscopy analyses (Min et al., 2004).

Immunoblot analyses and protein oxidation detection. Whole-cell or tissue extracts $(30 \mu \mathrm{g})$ were subjected to SDS-PAGE and immunoblotting as previously described (Min et al., 2004). The primary antibodies used were specific to GFAP (1:1000), MBP (1:800), proteolipid protein (PLP) (MAB388; 1:100; Chemicon International), or $\beta$-actin (CP01; 1:20,000; Calbiochem). The protein oxidation was determined using Chemicon's OxyBlot Oxidized Protein Detection kit and protocols provided. Briefly, protein lysates were derivatized (carbonyl groups) using DNPH (2,4-dinitrophenylhydrazine) reagents. Lysates were separated by SDS-PAGE, and after transfer to blotting membrane, blots were incubated with primary antibody to attached 2,4-dinitrophenol (DNP) moiety of the proteins. Oxidized molecular weight markers were also included in the kit. Detection sensitivity is $10 \mathrm{fmol}$ of dinitrophenyl residues on a single protein.

Mouse embryo fibroblasts, primary astrocyte and neuronal cultures, stress treatments, and 3-(4,5-dimethylthiazol-2-yl)-2,5-diphenyltetrazolium bromide assays. Mouse embryo fibroblasts (MEFs) were prepared from embryonic day 13.5 (E13.5) after timed pregnancies. MEFs were transformed using plasmids containing SV40 large T antigen and were cultured in DMEM supplemented with $10 \%$ heat-inactivated fetal calf serum (FCS) (Tu et al., 2006). Cortical astrocyte cultures were established from postnatal day 2 mice. Brains were extracted and separated from meninges, and the cortices were minced and treated with $0.09 \%$ trypsin for $20 \mathrm{~min}$ at $37^{\circ} \mathrm{C}$. After centrifugation, cells were resuspended in medium containing Eagle's MEM (EMEM) supplemented with 20\% heatinactivated FCS, $21 \mathrm{~mm}$ glucose, and $10 \mathrm{ng} / \mathrm{ml} \mathrm{EGF}$ (epidermal growth factor) (Peprotech, Rocky Hill, NJ). For primary neurons, we used cortices from E18 embryos. Cortices were digested with papain and tissue digestion was inhibited with trypsin inhibitor and cells were plated on poly-L-lysine-coated six-well plates or coverslips. Plating medium consisted of EMEM supplemented with 10\% FCS and N2 supplement (Invitrogen, Carlsbad, CA). Cultures were used after $3 \mathrm{~d}$ and the percentage of astrocytes (GFAP positive) in neuronal cultures was $<10 \%$. For stress treatments, astrocytes were seeded in $60 \mathrm{~mm}$ dishes until subconfluent, and then trypsinized and replated on coverslips precoated with poly-Dlysine at a density of $5 \times 10^{4}$ cells. Cultures were subjected to specific stress conditions as follows: for glucose deprivation, the growth medium was exchanged with a balanced salt solution (BSS) that lacked glucose. For anoxia treatment, cells were plated in an anoxic chamber $(0 \%$ oxygen) in an atmosphere of $95 \%$ nitrogen and $5 \% \mathrm{CO}_{2}$. For ischemia treatment, cells were placed in an anoxic chamber and incubated in the medium with glucose-free BSS. Untreated control cells were plated in complete medium. For 3-(4,5-dimethylthiazol-2-yl)-2,5-diphenyltetra- zolium bromide (MTT) assays, the Vibrant MTT (V13154) Cell Proliferation Assay kit (Invitrogen) was used. The medium was removed from culture plates and $100 \mu \mathrm{l}$ of DMEM without phenol red containing MTT was added. Cells were incubated at $37^{\circ} \mathrm{C}$ plus $5 \% \mathrm{CO}_{2}$ for $4 \mathrm{~h}$. The MTT-containing medium was resolved, and purple formazan crystals were dissolved by adding $100 \mu \mathrm{l}$ of SDS- $\mathrm{HCl}$ solution $(1 \mathrm{~g} \mathrm{SDS} / 10 \mathrm{ml}$ of $0.01 \mathrm{M} \mathrm{HCl}$ ). The microplates were incubated at $37^{\circ} \mathrm{C}$ for $6 \mathrm{~h}$, and absorbance was measured at $570 \mathrm{~nm}$.

BrdU labeling. To determine cellular proliferation in situ, $0.05 \mathrm{mg}$ of BrdU per gram of body weight was injected intraperitoneally into mice. Two hours after injection, spinal cords were postfixed overnight in $2 \%$ PFA containing $0.1 \mathrm{~m}$ lysine and $0.01 \mathrm{~m}$ sodium meta-periodate. After cytoprotection of tissues in $0.1 \mathrm{~m}$ phosphate buffer ( $\mathrm{pH} 7.4$ ) containing $15 \%$ sucrose, tissues were frozen in OCT and cryosectioned $(10 \mathrm{~mm})$. The Animal Research kit (K3954; DakoCytomation) was used to detect BrdU-positive cells.

Magnetic resonance imaging. Images of mice were acquired using a Bruker (Billerica, MA) 7T PharmaScan MRI. Two sets of highresolution, T2-weighted coronal images were acquired for four wild-type and six $h s f 1^{-1-}$ mice for use in brain segmentation, using a rapid acquisition with relaxation enhancement sequence (echo time, $42 \mathrm{~ms}$; repetition time, $5 \mathrm{~s}$; echo train, 8 ; field of view, $30 \times 30 \mathrm{~mm}$; 16 slices; slice thickness, $0.5 \mathrm{~mm}$; skip, $0.5 \mathrm{~mm}$; $256 \times 256$ matrix; number of excitations, 4; scan duration, $10 \mathrm{~min} 40 \mathrm{~s}$ ). The position of the first slice for the second set was offset from the first set by $0.5 \mathrm{~mm}$, allowing both sets to be incorporated into a single, interleaved three-dimensional image volume. This composite image volume covered a $16 \mathrm{~mm}$ length of brain tissue along the coronal axis, encompassing most or all of the olfactory lobe to the anterior cerebellum. Image intensity for each image set was slightly different, resulting mainly from receiver gain settings determined during an automatic prescan stage in the scanning sequence. The process of combining the two image sets into one proceeded as follows. Histograms of pixel image intensity were calculated for each image set using identical intensity bins, after multiplying one of the images sets by a gain factor $(g)$. If the two histograms were identical after multiplication with a gain factor, the number of pixels in a given bin should be equal between both histograms. The logarithm of the number of pixels belonging to each bin $\left(\mathrm{ln}_{\text {bin }}\right)$ was taken, and the difference in $\ln _{\text {bin }}$ between both histograms was computed for each bin. The absolute values of these differences were summed over all bins, giving a measure of difference between the histograms $\left(h_{\text {diff }}\right)$ that should be minimized for the appropriate gain factor. Finally, $g$ was adjusted in steps between 0.6 and 1.2; the value of $g$ yielding the minimum of $h_{\text {diff }}$ was accepted and the intensity of even-numbered slices was multiplied by $g$. After adjustment of the slice-to-slice intensities, both lateral ventricles and third ventricle (dorsal and medial) were segmented using MRIcro (Rorden and Brett, 2002). The fourth ventricle was not measured, because it was not fully present in all mouse images. After the image intensity was thresholded to segment ventricles coarsely, segmented regions of interest were drawn manually to define the ventricular boundaries more precisely. Additionally, the mouse cerebrum was segmented. A significant portion of the cerebrum was used to calculate a ventricular volume fraction, consisting of the ventricular volume divided by the partial brain volume. The brain volume used for normalization covered a region beginning with the first slice posterior to the juncture of the olfactory bulb to the most posterior slice that displayed the corpus callosum distinctly. This volume was defined for ease of measurement and was visible for all mice.

Behavioral studies. To test for motor function, we measured the ability of mice to balance on a $1.2 \mathrm{~cm}$ diameter round bar fixed at a height of 40 $\mathrm{cm}$ (Sereda et al., 1996). We assessed $h s \mathrm{fl}^{-1-}$ and age-matched controls from 4 weeks to 18 months of age. The time in seconds that animals remained on the bar was monitored. In a series of four trials, a maximum of 3 min per trial was allowed, and the longest time each animal remained on the bar was recorded. Number of mice used were as follows: 7 wild type and $10 \mathrm{hsf1} \mathrm{I}^{-1-}$ at $4-12$ weeks of age; 7 wild type and $10 \mathrm{hsf1^{-1- }}$ at $3-6$ months of age; 7 wild type and $11 \mathrm{hsf1^{-1- }}$ at $6-12$ months of age; and 10 wild type and $32 \mathrm{hsf1^{-1- }}$ at 12-18 months of age.

Statistical analyses. All experiments were performed at least three times. Number of embryos or mice used for each time point and/or 


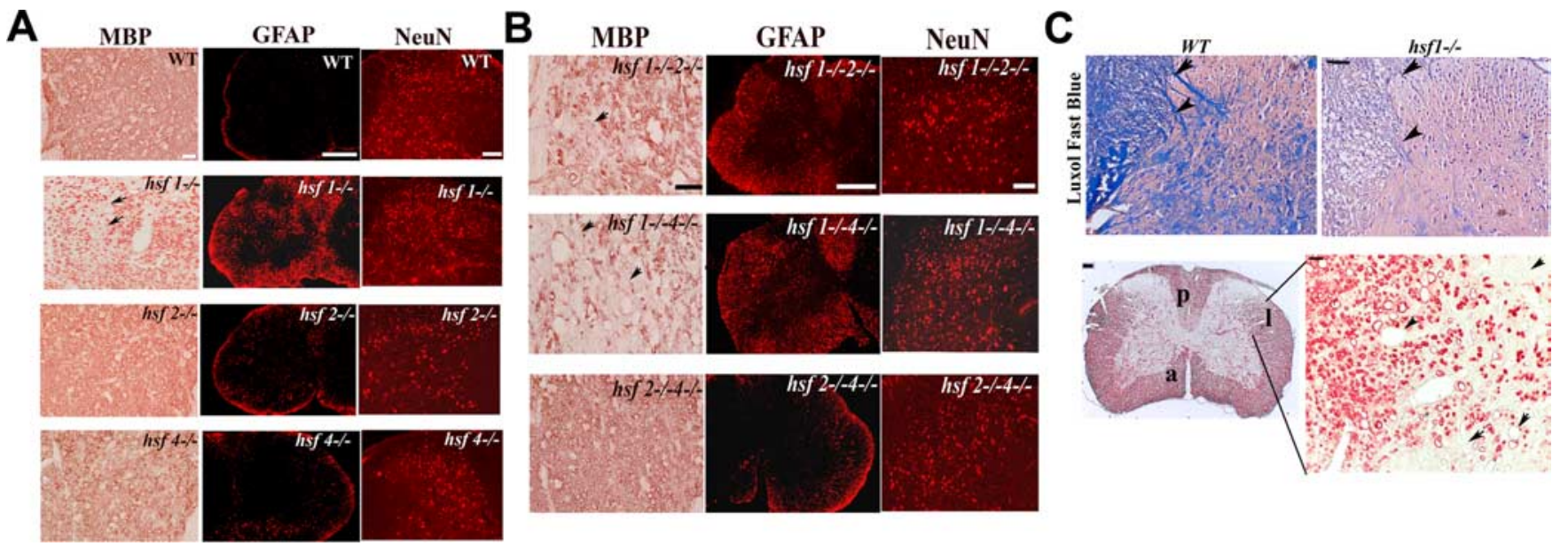

Figure 1. Demyelination and astrogliosis in $h s f 1^{-1-}$ mice. $A, B$, Cross sections of the cervical region of the spinal cords (entire or the posterior funiculus) from wild-type (WT), $h s f 1, h s f 2, h s f 4$, hsf1hsf2, hsf2hsf4, or hsf1hsf4-deficient mice at 8 weeks of age. Tissue sections were analyzed after immunohistochemical staining using antibodies to MBP, GFAP, or NeuN. Scale bars: MBP, $50 \mu \mathrm{m}$; GFAP, $500 \mu \mathrm{m}$; NeuN, $100 \mu \mathrm{m}$. C, High magnification of the spinal cord (posterior funiculus) presented for wild-type (WT) and hsf1 ${ }^{-1-}$ mice to show that Luxol Fast Blue (LFB) staining of myelin is less pronounced in $h s f 1^{-1-}$ mice (arrows). Scale bar, $50 \mu \mathrm{m}$. C, Bottom panels, Cross section of the spinal cord of $h s f 1^{-1-}$ mouse immunostained with MBP. p, a, and I indicate three areas of the spinal cord: $p$, posterior funiculus; a, anterior funiculus; and I, lateral funiculus. $p$ and I depict areas with reduced MBP immunostaining in $h s f 1^{-1-}$ spinal cord. The right panel depicts higher magnification of a section of lateral funiculus presented in the left panel. The arrowheads in the right panel indicate demyelinated (less MBP stained) and vacuolated myelin sheath. Scale bars: left panel, $100 \mu \mathrm{m}$; right panel, $50 \mu \mathrm{m}$.

genotype was $n=3-10$. Multiple sections of tissues were analyzed for each histological or immunohistological analyses. For statistical analyses, we used mean \pm SD and unpaired two-tailed Student's $t$ test unless otherwise indicated.

\section{Results}

Age-dependent demyelination and astrogliosis in hsf-deficient mice

Hsf1 is expressed in neurons, astrocytes, and oligodendrocytes (Walsh et al., 1997; Stacchiotti et al., 1999), whereas Hsf2 is expressed in neurons and glia and the developing cerebral cortex (Stacchiotti et al., 1999; G. Wang et al., 2003; Chang et al., 2006) and Hsf4 is expressed in CNS of developing embryos, certain neuronal cell population, but not in astrocytes (Hu and Mivechi, 2006) (data not shown). To examine the consequences of hsf deficiency in the CNS, we examined cross sections of the spinal cord after immunohistochemical staining of MBP, a component of the myelin membrane. We found reduced MBP immunostaining in 8-week-old $h s f 1^{-1-}$ mice, and more severely in 8-week-old mice deficient in either $h s f 1$ and $h s f 2$, or $h s f 1$ and $h s f 4$ genes (Fig. $1 A, B$, left panels; high magnification of the posterior funiculi is presented). The observed demyelination in 8-week-old $h s f 1^{-1-}$ mice was mild, but progressed with age (described below). The reduced myelination was not observed in the wild-type mice, or mice that were deficient in either the $h s f 2$ or $h s f 4$ gene (Fig. $1 A$ ). As the high magnification of the data presented in the left panel of Figure $1 A$ indicate, the $h s f 1^{-l-}$ spinal cord also exhibited weaker Luxol Fast Blue staining, which is an indication of the presence of less myelin (Fig. 1C, arrows; portion of the posterior funiculi is presented). In addition, MBP immunostaining of the sections of the entire spinal cord of $h s f 1^{-/-}$mice indicated that the posterior funiculi were most affected (Fig. $1 C$, bottom panel; area labeled as "p"). The lateral funiculi were also affected as presented in low (Fig. $1 C$, area labeled as "l") and high magnifications (Fig. $1 C$, bottom right panel). There were numbers of vacuolated myelin sheath in the spinal cord of $h s f 1^{-1-}$ mice in addition to demyelinated areas (Fig. $1 C$, bottom right panel, arrowheads). The anterior funiculi were less affected (Fig. $1 C$, labeled as "a"). Extensive analyses of sections derived from cervical, thoracic, or lumbar regions of the spinal cord from the cohort of 8- to 10 -week-old mice deficient in single or multiple $h s f s$ revealed that the onset of demyelination is after P18 and can be detected at 8-10 weeks of age, and $h s f 1$ is the critical $h s f$ that is required for the proper maintenance of myelin. However, we observed some dysmyelination in the sections of the CNS at P18, a peak period of myelination in the absence of both $h s f 1$ and $h s f 2$ genes (data not shown). The dysmyelination was not observed in $h s f 1^{-1-}$ mice at P18 (data not shown). The mechanism of dysmyelination in $h s f 1^{-1-} h s f 2^{-1-}$ mice could not be pursued further because of the reduced live birth in this genetic combination.

To further investigate whether there were gross alterations in astrocyte or neuron cell populations in mice deficient in $h s f 1$, or other $h s f s$, we immunostained sections of the adult spinal cord prepared from wild-type or $h s f 1^{-l-}$ mice using antibodies to GFAP, an astrocyte-specific marker, or to NeuN, a neuronspecific marker. Astrogliosis was observed in the tissues prepared from cross sections of the spinal cord (and brain) (see below) after staining with GFAP in the absence of the $h s f 1$ gene, when compared with age-matched control mice (Fig. $1 \mathrm{~A}$, middle panels). Astrogliosis was also severe in other knock-out mice combinations that also lacked the $h s f l$ gene, that is, mice deficient in the $h s f 1 h s f 2$, or $h s f 1 h s f 4$ genes (Fig. $1 B$, middle panels). No comparable defects were observed in $h s f 2, h s f 4$, or $h s f 2 h s f 4$-deficient mice (Fig. $1 A, B$, middle panels). These results indicate the presence of demyelination and astrogliosis in $h s f 1^{-1-}$ mice, which we found to be progressive and more severe at older age in these mice (see below). Close examination and quantitation of the NeuN staining of the tissue sections of the spinal cord showed no obvious neuronal cell loss (Fig. $1 A, B$ ) (data not shown). Immunohistochemical staining and quantitation of the NeuN-positive cells in the hippocampus area where neurons spread evenly, as well as other regions of the brain also showed no gross changes in neuronal cell populations (data not shown). This result indicates that neuronal death is not a prominent phenotype in $h s f 1^{-/-}$adult mice.

To further determine whether there was an age-dependent astrogliosis, analyses were performed where the numbers of as- 
trocytes were quantitated in cross sections of the spinal cord after immunostaining with GFAP (Fig. 2A,B). Results indicate that there was an age-dependent increase (2- to 2.5-fold) in the numbers of astrocytes in the spinal cord of $h s f 1^{-1-}$ mice or in mice deficient in hsflhsf2 or hsflhsf4 (Fig. 2A,B).

Because $h s f 1$ proved to be the critical $h s f$ gene whose deficiency leads to demyelination and astrogliosis, we conducted the subsequent experiments with $h s f 1^{-/-}$ mice. Therefore, we quantitated the number of NG2- or NeuN-positive cells in the cross sections of the spinal cord at $\mathrm{P} 0$ and P18, or in 8-week- or 3- to 5-month-old wild-type and $h s f 1^{-1-}$ mice. We found no statistically significant differences in the number of these cells between wild-type or $h s f 1^{-1-}$ mice (Fig. 2C,D).

To determine the high-resolution structural abnormalities in the spinal cord of $h s f 1^{-l-}$ mice, we performed transmission electron microscopic analyses. Thus, we analyzed mice at P18, the age that is the peak of myelination, young adult mice at 10-14 weeks of age, and mice at 5.5-16 months of age. Results indicate that $h s f 1^{-1-}$ and wild-type mice exhibited comparable levels of myelination at P18 (data not shown). These results also suggest that the developmental program of myelination in $h s f 1^{-1-}$ mice is essentially unaffected and compact myelin of similar thickness is assembled surrounding both small and large axons. However, an agedependent demyelination was evident in the spinal cord of $h s f 1^{-/-}$mice at $10-14$ weeks of age and at 5.5-16 months of age compared with wild-type mice. At 10-14 weeks of age and older, we observed axons with reduced myelin in $h s f 1^{-/-}$ mice. These abnormalities were not observed in wild-type mice (Fig. 3A). Quantitation of the number of axons with affected myelin (thinning or absent) in sections of the spinal cord that we examined revealed that $h s f 1^{-1-}$ mice contained significantly higher percentages of axons with reduced myelin at 14 weeks of age and older (Fig. $3 B$ ).

The age-dependent demyelination and astrogliosis observed in $h s f 1^{-l-}$ mice was not unique to the spinal cord, but was also observed in histological sections prepared from the brain (Fig. 4). Coronal sections of the brains of 8-week- or 1.5-year-old $h s f 1^{-1-}$ or wild-type mice were immunostained with antibody to GFAP (Fig. 4A) or MBP (B). The results indicate evidence of hypertrophic astrocytes and areas of severe demyelination prominently in $h s f 1^{-l-} 1$ - or 1.5-year-old mice (Fig. 4, arrows). Astrogliosis was detected in the region surrounding the lateral ventricles (Fig. $4 A$ ). Areas rich in myelinated axons such as corpus callosum were specifically affected in aged mice (Fig. $4 B$, arrows depict retrosplenial granular cortex/corpus callosum, hippocampus area). The GFAP immunostaining of the sections of the cerebellum of
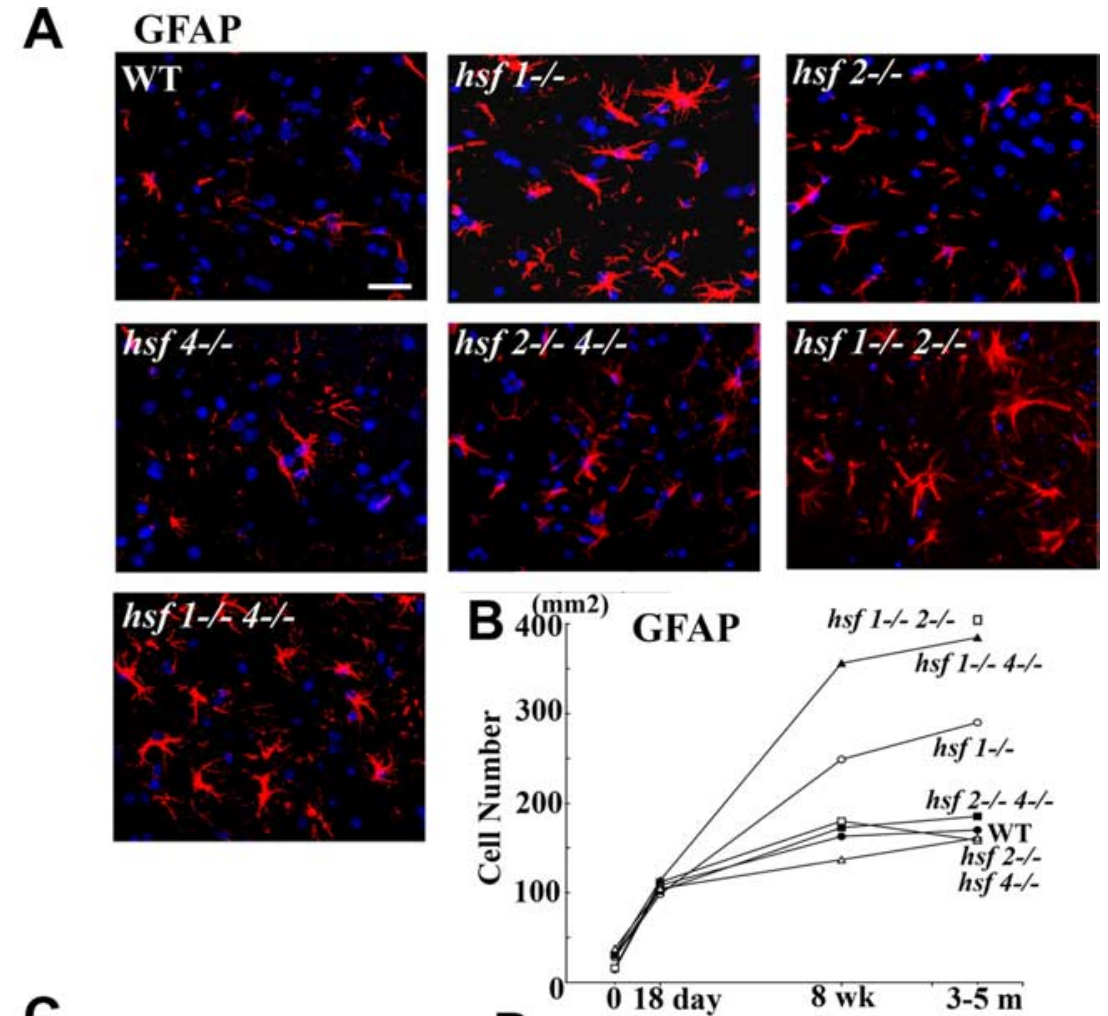

D

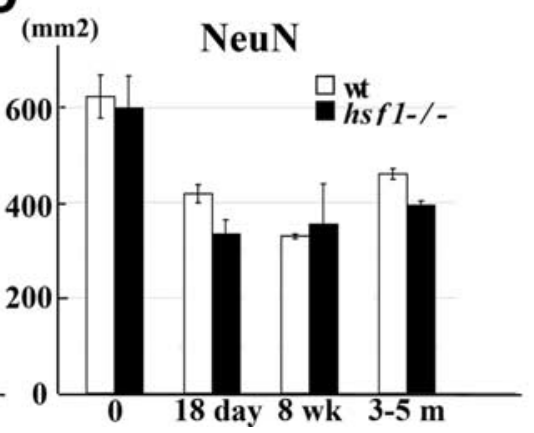

Figure 2. Age-dependent astrogliosis in $h s f 1^{-1-}$ mice. $A, B$, Cross sections of the cervical region of the spinal cords from ( antibody to NG2 or NeuN. The number of immunopositive cells in each section was quantitated and reported per square millimeter ( $n=3$ mice). Error bars indicate SEM.

8- to 13 -week-old wild-type or $h s f 1^{-1-}$ mice also indicated the presence of activated astrocytes in $h s f 1^{-1-}$ mice (data not shown). Structural abnormalities were also confirmed using magnetic resonance imaging (MRI) of 1.5 -year-old $h s f 1^{-1-}$ or wild-type mice. Interestingly, MRI analyses of the aged $h s f 1^{-1-}$ mice show an ill defined corpus callosum consistent with the reduction of MBP immunostaining (Fig. 5A). Quantitative analyses of MRI images showed significant enlargement of the lateral and third ventricles in brain of $h s 1^{-1-}$ mice compared with wildtype mice (Fig. 5B).

To determine whether the levels of GFAP and MBP expression in the brains of 8 -week-old adult $h s f 1^{-1-}$ mice is consistent with immunohistochemistry data presented in Figures 1 and 2, immunoblot analysis of whole-brain extracts of wild-type or $h s f 1^{-1-}$ mice were performed using antibodies to each protein. The results indicate an increase in GFAP levels by $30 \%$ in total brain 


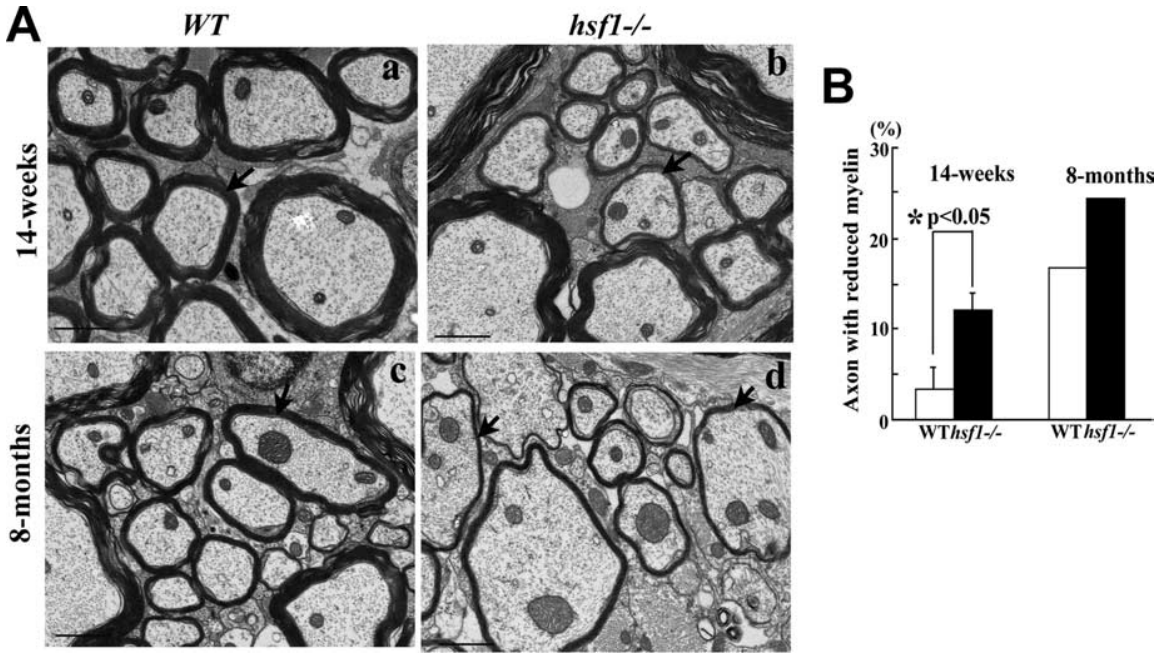

Figure 3. Electron microscopic analyses of $h s f 1^{-1-}$ spinal cord show demyelination with age. $A$, Electron microscopy analyses of cross sections of the thoracic region (anterior funiculus) of the spinal cord from wild-type (WT) (a) or hsf ${ }^{-1-}$ (b) mice at 14 weeks of age, or WT (c) or hsf1 ${ }^{-1-}(\boldsymbol{d})$ at 8 months of age. The arrows in $\boldsymbol{a}$ and $\boldsymbol{b}$ indicate the presence of axons with reduced myelin in young $h s f 1^{-1-}$ mice, and the arrows in $c$ and $\boldsymbol{d}$ indicate the presence of axons with reduced myelin in old $h s f 1^{-1-}$ mice. Scale bar, $1 \mu \mathrm{m}$. $\boldsymbol{B}$, Axons with reduced myelin were counted in EM sections of the spinal cord prepared from wild-type or hsf1 ${ }^{-1-}$ mice at 14 weeks of age and 8 months of age, and the graphs are reported as percentages of axons with reduced myelin. Note that most affected axons in terms of reduced myelin were those between 1 and $5 \mu \mathrm{m}$ in diameter. Myelination in axons $>5$ $\mu \mathrm{m}$ was less affected. The quantity of axons $<1 \mu \mathrm{m}$ in $h s f 1^{-1-}$ mice appeared reduced compared with wild-type mice. Error bars indicate SEM.

extract derived from 8 -week-old $h s f 1^{-1-}$ compared with wildtype mice (Fig. 6A). A reduction in $21.5 \mathrm{kDa}(26 \%), 18.5 \mathrm{kDa}$ (36\%), $17 \mathrm{kDa}(40 \%)$, and $14 \mathrm{kDa}(48 \%) \mathrm{MBP}$ species were evident in $h s f 1^{-1-}$ mice compared with wild-type mice (Fig. $6 \mathrm{~A}$ ). Reduction in the level of PLP was less evident in $h s f 1^{-1-}$ compared with wild-type brain (4\%). An indication of changes in GFAP and MBP expression was observed in immunoblot analyses of different regions of the brain of an 8-week-old wild-type and $h s \mathrm{fl}^{-1-}$ mice (Fig. $6 \mathrm{~B}$ ). The results indicate that the increase in GFAP staining in $h s f 1^{-1-}$ mice are pronounced in hippocampus $(61 \%)$, cortex $(92 \%)$, and cerebellum (80\%) compared with wild type. Reductions in the level of PLP were less pronounced, whereas there was reduction in $14 \mathrm{kDa} \mathrm{MBP}$ isoform in $h s f 1^{-l-}$ brain extracts from hippocampus (18\%) and cortex (28\%) (Fig. $6 B)$.

\section{$h s f 1^{-/-}$mice exhibit deficiencies in motor control tests}

hsfl-deficient mice do not exhibit age-dependent paralysis or shortened life span. However, we wanted to determine whether there was any behavioral deficit in $h s f 1^{-1-}$ mice ranging from $1-3$ to $12-18$ months of age (Fig. 7). Specifically, we performed motor control tests in a cohort of $h s f 1^{-1-}$ and wild-type mice. Analyses of the data indicate that at 1-3 months of age, there was no significant difference in motor behavior between wild-type and $h s f 1^{-1-}$ mice. However, at 6-18 months of age, $h s f 1^{-/-}$mice had significantly reduced ability to grasp with their hindlimb and stay on the bar when compared with the wild-type mice. This test is sensitive to damage to hippocampal and basal ganglia and hindlimb dysfunction. We also performed more extensive behavioral studies with $h s f 1^{-l-}$ mice at 5.5 months of age. The results show that $h s f 1^{-l-}$ mice exhibited significant deficiencies in the first trial of the rotarod test, which requires a high degree of sensimotor coordination and is sensitive to damage to the cerebellum and basal ganglia. However, at this age, $h s f 1^{-1-}$ mice did not show significant alterations from the heterozygous littermates in other tests, such as Y-maze (spontaneous alterations or two-trial recognition memory tests), fear conditioning (contextdependent freezing or cue-dependent freezing), or locomotor activity (data not shown). Interestingly, the 8-weekold $h s f 1^{-1-} h s f 2^{-1-}$ mice that exhibit a more severe phenotype in terms of demyelination showed significant deficiencies in Y-maze recognition memory task (total arm entries) (sensitive to hippocampal damage) and rotarod tests (in both days 1 and 2). The $h s f 1^{-1-} h s f 2^{-1-}$ mice did not show significant defects in fear-conditioning tests or prepulse inhibition tests (data not shown).

\section{Oligodendrocytes appear normal in hsf ${ }^{-/-}$mice}

Oligodendrocyte progenitor cells (OPCs) are generated in the ventricular zone of the embryonic spinal cord and undergo maturation to myelin-producing oligodendrocytes by P18. In Figure $2 C$, we presented quantitative analyses showing that the NG2-positive cells in the cervical region of the spinal cord in $h s f 1^{-1-}$ mice are comparable with wild-type mice at P0 to 5 months of age. Proliferating OPCs can also be identified by specific immunostaining of proteoglycan NG2 and BrdU labeling. To investigate whether $h s f 1^{-1-}$ mice were deficient in the number of OPCs generated during development, we determined the number of OPCs and BrdU-positive cells in the multiple regions of the spinal cord at P10 (Fig. 8). Quantitation analyses showed that the number of OPCs and BrdU-positive cells in wild-type versus $h s f 1^{-1-}$ mice was not significantly different (data not shown). Coimmunostaining of NG2 and TUNEL to detect apoptotic OPCs in the sections of the spinal cord did not reveal any significant increase in OPCs undergoing apoptosis in $h s f 1^{-1-}$ versus wild-type young mice (data not shown). Immunostaining and quantitation of the number of more mature oligodendrocytes using O4-positive cells in sections of the spinal cord of 8 - to 13 -week-old wild-type or $h s f 1^{-1-}$ mice also indicated no significant difference (data not shown). We also performed quantitative analyses of O4-positive and TUNELpositive oligodendrocytes in cervical region of the spinal cord at $8-13$ weeks of age in wild-type or $h s f 1^{-/-}$mice. The results indicated no $\mathrm{O} 4$ and TUNEL-positive cells in either wild-type or $h s f 1^{-1-}$ mice at this age (data not shown). However, at 1.5 years of age, there was a significant number of TUNEL-positive cells in tissue sections of the spinal cord in $h s f 1^{-1-}$ mice, few of which were also CC1 positive (oligodendrocytes), but the differences between $h s f 1^{-/-}$and wild-type mice were not statistically significant (Fig. 9).

As noted earlier, while performing TUNEL assays in aged $h s f 1^{-1-}$ spinal cord sections, we noted many apoptotic cells in the anterior white matter of the spinal cord that did not colocalize with CC1-positive cells. To identify these apoptotic cells, we performed double immunostaining with GFAP and TUNEL, or NeuN and TUNEL, and quantitated the number of apoptotic cells positive for each staining. The results are presented in Figure 
9 , and the data indicate that the majority of the cells undergoing apoptosis were positive for GFAP. Together, these results indicate that, in $h s f 1^{-/-}$aged mice, preoligodendrocytes, or CC1-positive oligodendrocytes, do not undergo substantial death but that GFAP-positive astrocytes do.

Presence of reactive microglia in aging hsf1 ${ }^{-/-}$spinal cord

Because the sections of the spinal cord in 8-week-old $h s f 1^{-1-}$ mice exhibited astrogliosis, we determined the presence of activated microglia cell population in sections of the spinal cord of these mice, using antibody to Mac3. The results showed no significant numbers of activated microglia in the $h s \mathrm{fl}^{-1-}$ compared with wild-type mice. However, there was a significant number of Mac3-immunoreactive cells in the spinal cord of $h s f 1^{-/-}$mice at 1 year of age (Fig. 10). Therefore, progressive demyelination in $h s f 1^{-/-}$mice is accompanied by an increase in activated microglia.

\section{$h s f 1^{-/-}$MEFs exhibit deficiency in protein degradation and accumulate ubiquitinated green fluorescent protein and aggregated polyQ-green \\ fluorescent protein}

Hsfl regulates the stress inducibility of Hsps, and number of Hsps has been shown to be involved in ubiquitin proteasomedependent protein degradation, and reduction in their level of expression in cells has been shown to affect both protein degradation and folding, leading to the formation of insoluble protein aggregates. To examine whether $h s f 1^{-/-}$cells exhibit defects in protein quality control mechanisms, we transiently transfected wild-type or $h s f 1^{-/-}$MEFs with plasmids containing Ub-M-green fluorescent protein (GFP), which does not possess a degradation signal and therefore is as stable as the unmodified GFP, or with plasmids containing UbR-GFP, which contains an arginine as a destabilizing amino acid and therefore has a short half-life (Dantuma et al., 2000). Fortyeight hours after transfection, flow cytometric analyses were performed to detect the number of GFP-positive cells. The results indicate that $h s f 1^{-/-}$cells expressed higher percentages of both Ub-M-GFP (wild type, $10.2 \%$, vs $\left.h s f 1^{-1-}, 15 \%\right)$ - or Ub-R-GFP (wild type, $1.1 \%$, vs $h s f 1^{-/-}, 10.4 \%$ )-positive cells (Fig. 11A). These results were also confirmed using immunoblotting and pulse-chase experiments to detect the level of Ub-R-GFP accumulation and its rate of decay in wild-type versus $h s \mathrm{fl}^{-1-}$ cells. Immunoblotting experiments indicated a $25 \%$ increase in Ub-M-GFP expression in $h s 1^{-/-}$versus wild-type cells. In the case of Ub-R-GFP, there was a sevenfold increase in the level of Ub-R-GFP in $h s f 1^{-/-}$cells versus wild-type cells

B
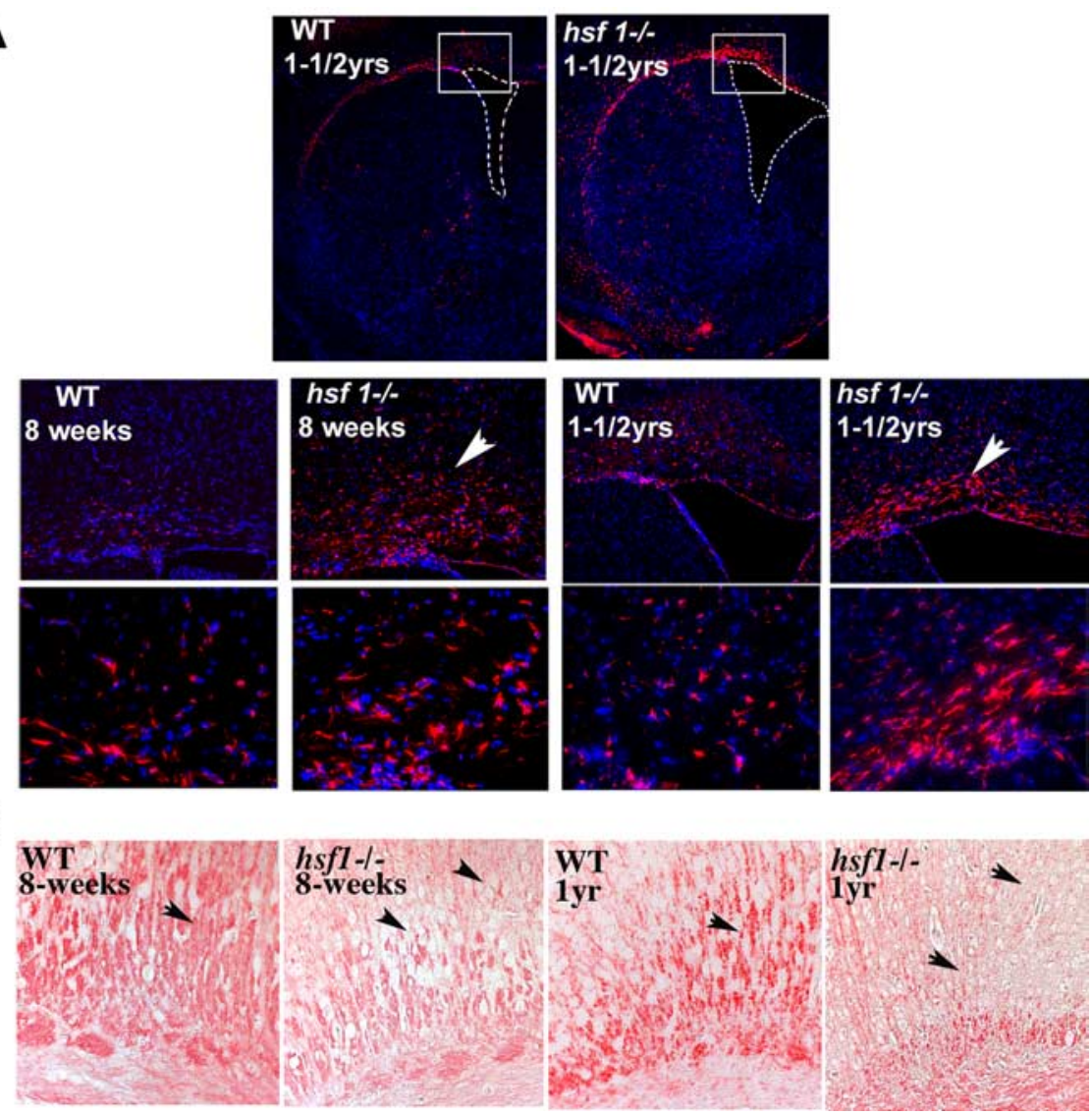

Figure 4. Age-dependent degeneration of $h s f 1^{-1-}$ brain. $A, B$, Immunohistochemical staining of coronal section of the brain (corpus callosum and lateral ventricles, dotted lines) using antibodies to GFAP $(\boldsymbol{A})$ (red fluorescent) or MBP $(\boldsymbol{B})$ from wild-type (WT) and $h s f 1^{-1-}$ mice at 8 weeks or $1-1.5$ years of age as indicated. The bottom panels of $A$ are higher magnification of boxed areas. The arrows in $\boldsymbol{A}$ depict areas with increased astrocytes in $h s f 1^{-1-}$ brain. The arrows in $\boldsymbol{B}$ indicate areas of demyelination in hsf1 ${ }^{-1-}$ brain compared with wild type. Magnification: $A, 25 \times$ (top), $100 \times($ middle), $250 \times($ bottom); $\boldsymbol{B}, 400 \times$. The nuclei in $A$ have been stained with DAPI (blue).
A
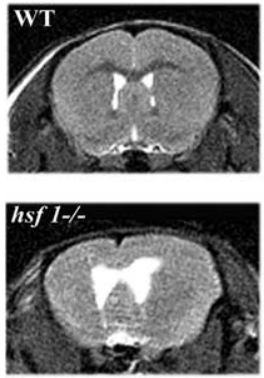
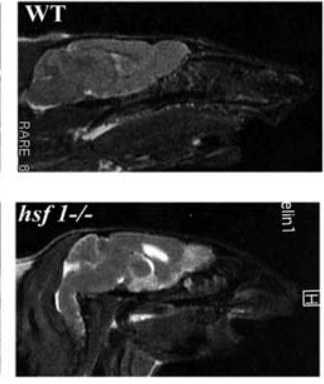

B

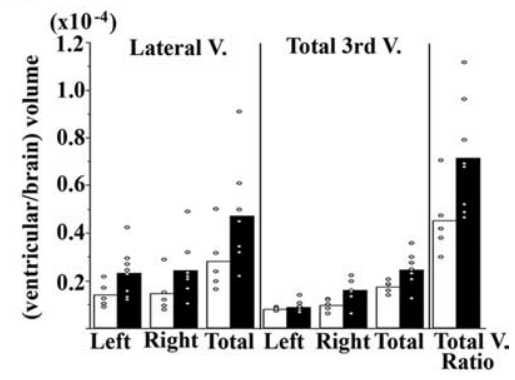

Figure 5. Aged $h s f 1^{-1-}$ mice show structural abnormality by magnetic resonance imaging analyses. $\boldsymbol{A}, \mathrm{MRl}$ images of the coronal (left) and sagittal (right) sections from the brain of wild-type (WT) or $h s f 1^{-1-}$ mice at 1.5 years of age. $B$, Quantitation (relative units) of lateral and third ventricles (V) of MRI images of wild-type and $h s f 1^{-1-}$ brain. The bars indicate median values. The $p$ value for total ventricle ratio in $h s f 1^{-1-}$ mice was significantly larger than wild type $(=0.05)$. The $p$ values for left and total lateral ventricles in $h s f 1^{-1-}$ mice were significantly larger than wild type $(=0.05)$. The $p$ values for dorsal and total third ventricles in $h s f 1^{-1-}$ mice were significantly larger than wild type $(=0.05)$. Note that some of the ventricle volumetric measurements are correlated. White bars, Wild type; filled bars, $h s f 1^{-1-}$.

(Fig. $11 B$ ). Pulse-chase experiments revealed that Ub-R-GFP decayed with a half-life of $\sim 70$ min in wild-type cells, whereas at this time point, $80 \%$ of the Ub-R-GFP was still present in $h s f 1^{-1-}$ cells (Fig. $11 C$ ). These experiments suggest that $h s f 1^{-1-}$ cells exhibit defects in the ubiquitin proteasome system and do not efficiently degrade ubiquitinated proteins compared with wild-type cells. 
A

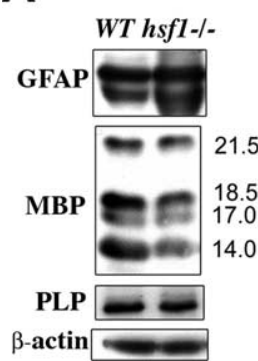

B

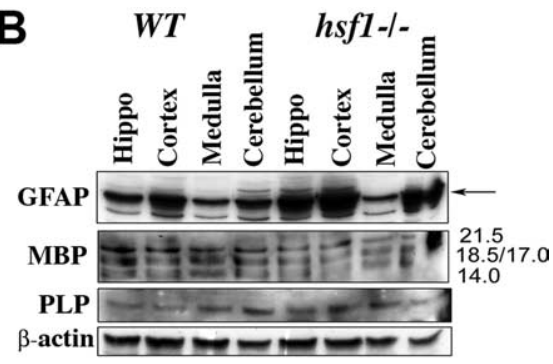

Figure 6. Alterations in the levels of GFAP and MBP in $h s f 1^{-1-}$ brain. $\boldsymbol{A}, \boldsymbol{B}$, Immunoblot analyses of total brain extracts $(30 \mu \mathrm{g}$ ) or extracts prepared from different regions of the brain (30 $\mu \mathrm{g}$ ) from 10-week-old wild-type (WT) or $h s f 1^{-1-}$ mice to detect GFAP, MAG (myelinassociated glycoprotein), MBP, or PLP. MBP contains multiple isoforms. $\beta$-Actin is shown as loading control.

A

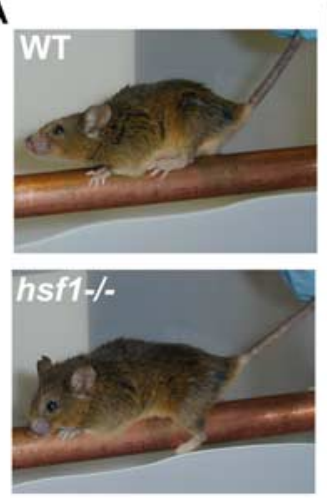

B

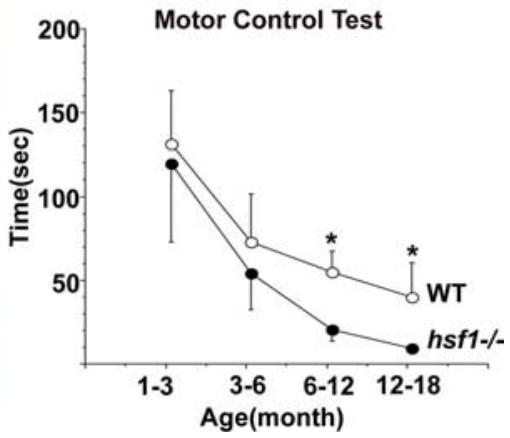

Figure 7. Defects in motor activity in aging $h s f 1^{-1-}$ mice. A, Photographs show the performance of 12- to 18-month-old wild-type (WT) and $h s f 1^{-1-}$ mice on bar tests. $\boldsymbol{B}$, Data for mice at 2 weeks to 18 months of age are plotted as time in seconds that mice were able to hold on to the bar. The asterisk indicates that $h s f 1^{-1-}$ mice were able to hold on to the bar for a significantly $(p<0.05)$ shorter amount of time than the wild-type mice of the same age group. Error bars indicate SEM.
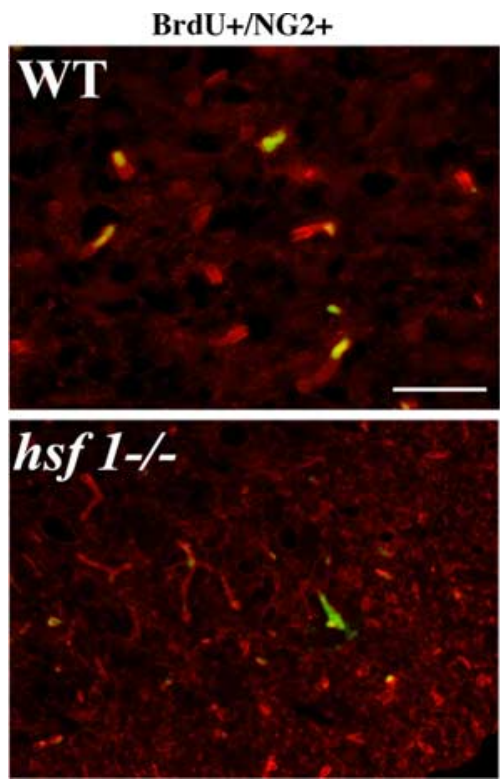

Figure 8. Normal proliferation of OPCs in $h s f 1^{-1-}$ mice. Immunofluorescence analyses of BrdU-labeled (green fluorescent) and NG2 (red fluorescent) OPCs in the cross sections of the spinal cord of wild-type (WT) and hsf1 ${ }^{-1-}$ mice at P10. Scale bar, $50 \mu \mathrm{m}$.

A
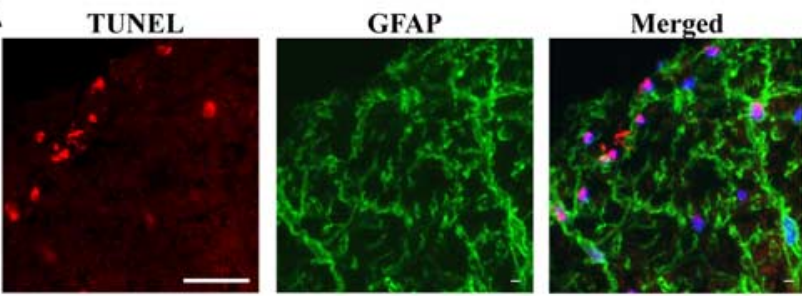

TUNEL
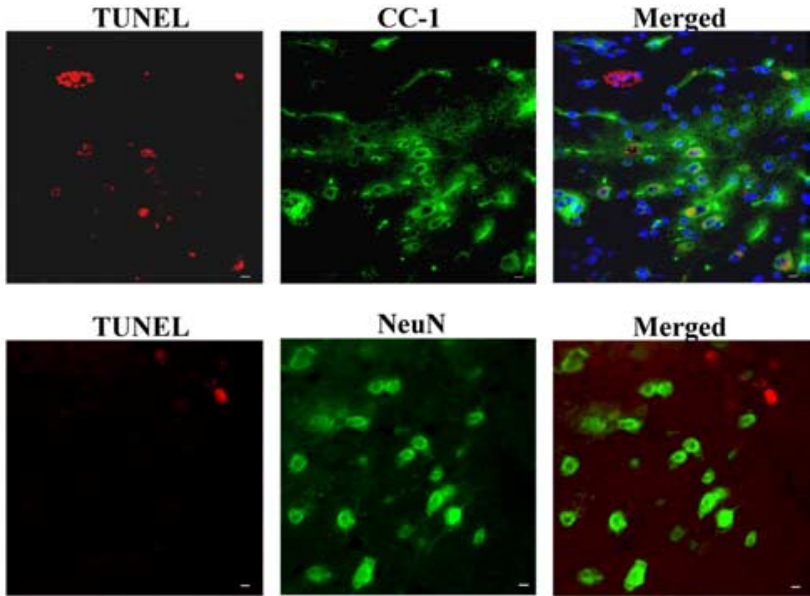

B

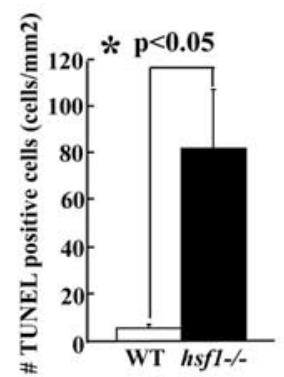

C

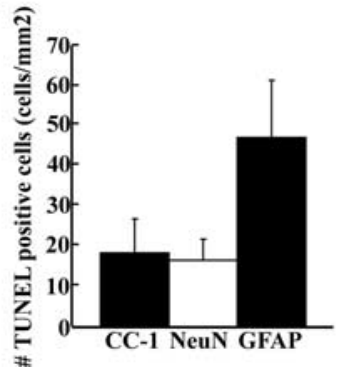

Figure 9. Increased apoptotic cells in the CNS of $h s f^{-1-}$ aged mice. A-C, Immunohistochemical staining of sections from cervical region of the spinal cord using antibody to $\mathrm{CC} 1$, NeuN, or GFAP to detect oligodendrocytes, neurons, or astrocytes, respectively. Apoptotic cells were stained with TUNEL (red fluorescent). Merged is the overlap of TUNEL, specific staining (green fluorescent) as indicated in each panel, and DAPI (blue fluorescent) to detect nucleus. Scale bar, $100 \mu \mathrm{m}$. B shows quantitation of the TUNEL-positive cells in tissue sections obtained from wild-type or $h s f 1^{-1-}$ mice at 1.5 years of age. ${ }^{*} p<0.05$. C presents quantitation of the TUNEL-positive cells in $\boldsymbol{A}$ of each cell type as indicated. Error bars indicate SEM.

Previous studies indicate that cells expressing proteins with an abnormal number of polyglutamines exhibit aggregation, and such aggregates cause toxicity to cells by sequestering the proteins that harbor normal numbers of polyglutamine repeats (Schaffar et al., 2004). Because $h s f 1^{-1-}$ MEFs accumulate ubiquitinated proteins, we performed experiments to determine whether cells deficient in $h s f 1$ exhibit an increase in the accumulation of abnormal glutamine repeats (Q103-GFP) when compared with wildtype cells. Wild-type or $h s f 1^{-1-}$ MEFs were transiently transfected with expression constructs encoding either Q25-GFP (normal number of glutamines) or Q103-GFP. Forty-eight hours after transfection, cells were analyzed by immunofluorescent microscopy and FACS analyses (Fig. 12). Quantitation of the results show that, whereas $3 \pm 0.5 \%$ of wild-type cells showed aggregates of Q25-GFP, $12 \pm 1 \%$ of $h s f 1^{-1-}$ cells showed Q25-GFP aggregates. The percentage of cells exhibiting aggregates increased significantly in $h s f 1^{-l-}$ cells that expressed Q103-GFP when compared with wild-type cells ( $15 \pm 1$ vs $73 \pm 2 \%)(p<0.05)$ (Fig. 
$12 A, B)$. The intensity of the GFP-positive $h s f 1^{-1-}$ cell populations expressing Q25GFP (wild-type, $1 \%$, vs $h s f 1^{-1-}, 3 \%$ ) or Q103-GFP (wild-type, 5\%, vs $h s f 1^{-1-}$, $29 \%$ ) was significantly higher compared with wild-type cells when analyzed by flow cytometry (Fig. 12C). Striking accumulation of large granules of Q103-GFP aggregates was evident in $h s f 1^{-l-}$ cells compared with smaller aggregates that accumulated in wild-type cells, which are presented in Figure $12 \mathrm{~A}$.

$h s f 1^{-/-}$brain cells, primary astrocytes, and neurons exhibit higher than wildtype levels of ubiquitinated proteins, and $h s f 1^{-/-}$astrocytes show increased sensitivity to

\section{oxidative stress}

The demyelination and astrogliosis that are observed in $h s f 1^{-l-}$ mice could potentially be the results of defects in some cell populations in the CNS (Scherer, 1997; Baumann and Pham-Dinh, 2001). Because $h s f 1^{-1-}$ MEFs exhibit reduced ability to degrade ubiquitinated proteins and accumulate higher levels and larger aggregates of proteins with an abnormal number of glutamines, we considered the possibility that $h s f 1^{-/-}$brain may also exhibit higher than normal levels of ubiquitinated proteins. Therefore, we compared the levels of ubiquitin in extracts of 8 -week-old wildtype, or $h s 1^{-l-}$ brain by immunoblotting. The data indicate that $h s f 1^{-1-}$ total brain extracts show 50\% increase in ubiquitinated proteins (Fig. 13). This increase in ubiquitinated proteins was also associated with an increase in the accumulation of higher molecular-weight species (Fig. 13; note the difference in the intensity between lanes indicated as wild type and $h s f 1^{-/-}$, and the arrow).

To further analyze whether $h s f 1^{-1-}$ cells derived from the CNS exhibit increased ubiquitinated proteins, primary astrocyte and neuronal cultures were established from wild-type or $h s f 1^{-l-}$ mice. The accumulation of ubiquitinated proteins in the primary neuronal cultures prepared from wild-type or $h s f 1^{-1-}$ mice was not significantly different (Fig. 13, middle panels). In addition, exposure of neurons to $2 \mathrm{~h}$ of anoxia did not change the level of ubiquitinated proteins (Fig. 13). However, untreated astrocytes showed 30\% increase in the ubiquitinated proteins in $h s f 1^{-1-}$ compared with wild-type, and ubiquitinated protein levels further increased by $30 \%$ after exposure of wild-type or $h s f 1^{-1-}$ astrocytes to $2 \mathrm{~h}$ of anoxia (Fig. 13).

Immunofluorescence analyses of primary astrocyte cultures also indicated a significant increase in the cytoplasmic staining of ubiquitinated proteins after exposure of the cells to $2 \mathrm{~h}$ of anoxia in $h s f 1^{-l-}$ cells compared with wild type (Fig. 14A,B). These results indicate that brain and astrocytes derived from $h s f 1^{-1-}$ mice accumulate elevated levels of ubiquitinated proteins and that astrocytes are more sensitive to oxidative stress and further
Mac-3
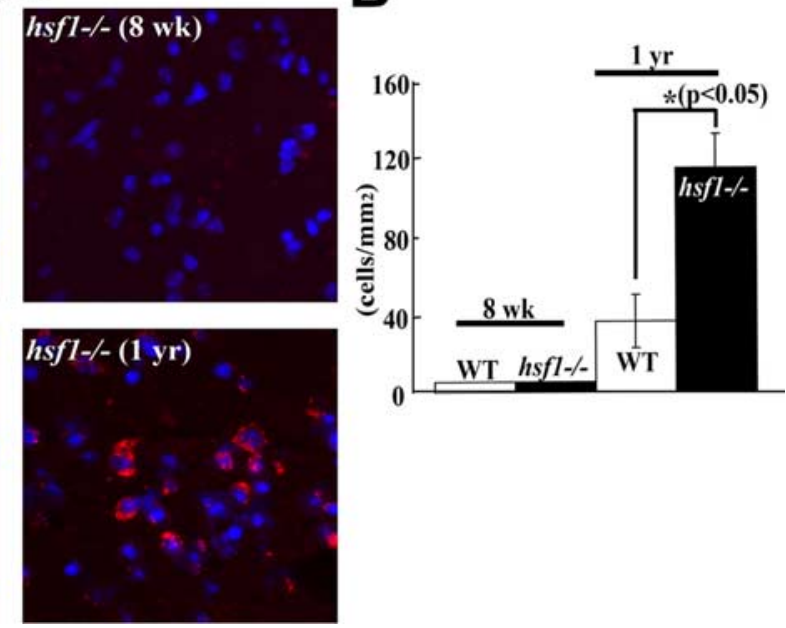
Figure 10. Reactive gliosis in $h s f 1^{-1-}$ aged mice. $A, B$, Immunohistochemical analysis of sections of the cervical region of the
spinal cord from 8-week-old or 1-year-old wild-type or $h s f 1^{-1-}$ mice using antibody to Mac3. Scale bar, $50 \mu$ m. Quantitation of the data are presented in $\boldsymbol{B}$. Error bars indicate SEM.
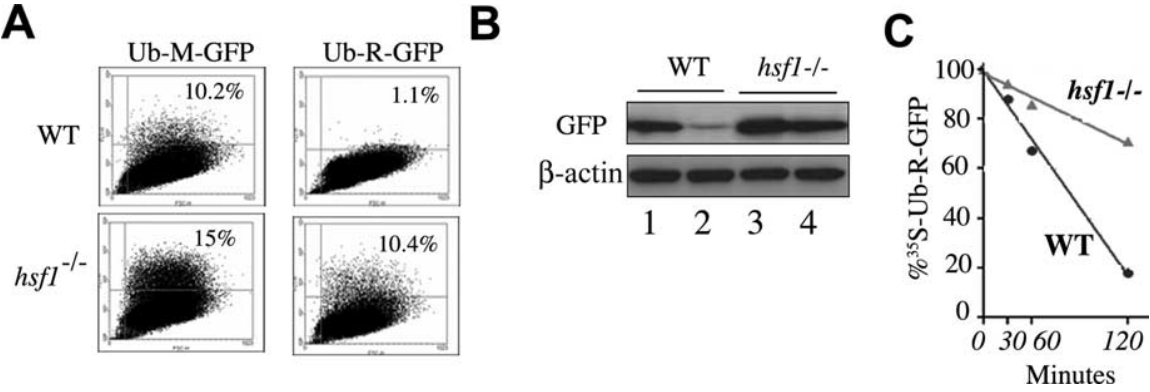

Figure 11. $h s f 1^{-1-}$ cells exhibit defects in ubiquitin-proteasome pathway. A, Flow cytometric analysis of transiently transing $\beta$-galactosidase as internal control for transfection frequency. GFP-positive cells are indicated in the top panel of each Ub-M-GFP or Ub-R-GFP (lanes 1 and 2, respectively) and hsf1 ${ }^{-1-}$ MEFs expressing Ub-M-GFP or Ub-R-GFP (lanes 3 and 4 were subjected to immunoprecipitation using antibody to GFP, and appropriate bands were quantitated for the presence of $\left[{ }^{35} \mathrm{~S}\right]$ methionine. The $y$-axis indicates the percentage of $\left[{ }^{35} \mathrm{~S}\right]$ methionine remaining compared with original labeled protein at the end of the labeling period.

accumulate ubiquitinated proteins in the cytoplasm; these often appeared as punctated granules and aggregates (Fig. 14B,C).

$\mathrm{Hsfl}$ is a stress-inducible transcription factor and is activated in response to heat shock and oxidative stress. To determine whether $h s f 1^{-1-}$ astrocytes exhibit increased sensitivity when they encounter low levels of glucose [glucose deprivation (GD)] or oxygen (anoxia) or both [oxygen-glucose deprivation (OGD)], primary astrocyte cultures were exposed to different periods of time to such culture conditions. A significant decrease in the viability of $h s f 1^{-1-}$ primary astrocytes was observed after exposure to low oxygen and glucose (OGD), or to low oxygen conditions when compared with wild-type cells (Fig. 15A). No significant differences were found between wild-type or $h s f 1^{-1-}$ cells when cells were exposed to low glucose (GD). Exposure of primary neuronal cultures to 4 and $8 \mathrm{~h}$ of anoxia indicate that $h s 1^{-l-}$ neurons were also more sensitive to anoxia treatment compared with wild-type cells; however, the increased sensitivity was not statistically significant (Fig. 15B). 


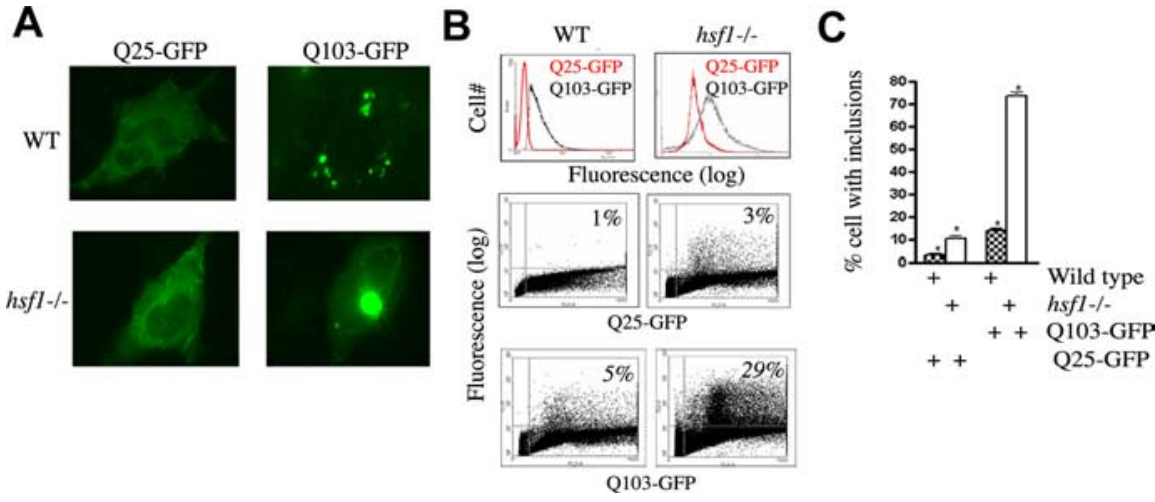

Figure 12. $\quad h s f 1^{-1-}$ cells exhibit increased aggregation of polyglutamine repeat proteins. $A, C$, Immunofluorescence analyses of wild-type or $h s f 1^{-1-}$ MEFs transiently transfected with expression vectors containing polyQ25-GFP or polyQ103-GFP. Transfected cells were fixed in 4\% paraformaldehyde for 15 min and visualized using fluorescent microscopy $(\boldsymbol{A})$. The percentage of cells containing polyQ-GFP aggregates from a total of $250 \mathrm{GFP}$-positive cells in wild-type or $h s f 1^{-1-}$ cells were quantitated (C). Error bars indicate SEM. B, Flow cytometric analyses of wild-type or $h s f 1^{-1-}$ MEFs $48 \mathrm{~h}$ after transient transfection with expression vectors containing polyQ25-GFP or poly0103-GFP and $\beta$-galactosidase as an internal control of transfection frequency. The top panels show cell number versus fluorescent intensity in wild-type versus $h s f 1^{-1-}$ cells expressing Q25GFP or Q103-GFP. The bottom two panels show GFP-positive cells (and percentages) in top panel of each quadrant for wild type versus $h s f 1^{-1-}$ for cells expressing Q25GFP or Q103-GFP.

\section{Brain \\ Neurons}

Control WT hsfl-/-
Control 2 hr Anoxia

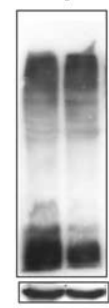

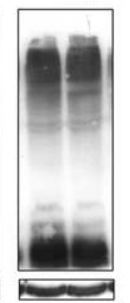

Astrocytes

Control 2h Anoxia WT hsfl-/- WT hsf1-/-

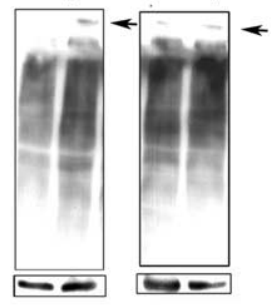

$\beta$-actin

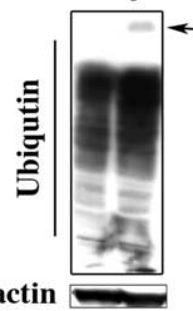

Figure 13. Increased accumulation of ubiquitinated proteins in $h s f 1^{-1-}$ brain and primary astrocytes. Immunoblot analyses $(30 \mu \mathrm{g})$ using antibody to detect ubiquitinated proteins in total brain extracts (left panels), cultured neurons (middle panels), or cultured astrocytes (right panels) prepared from wild-type or $h s f 1^{-1-}$ mice at 8 weeks of age (for total brain extract) or E18 (for neuron cultures) or P2 (for astrocyte cultures). Immunoblot analyses of samples after exposure to anoxia ( $0 \%$ oxygen) for $2 \mathrm{~h}$ are also presented. $\beta$-Actin was used as loading control.

\section{Elevated levels of protein oxidation in $h s f 1^{-/-}$brain, primary astrocytes, and neurons}

One of the essential functions of Hsf1 is to protect cells against environmental insults such as oxidative stress. Because we determined that $h s 1^{-1-}$ astrocytes were significantly more sensitive to oxidative stress than the wild-type cells, we performed analyses to determine whether proteins extracted from $h s f 1^{-l-}$ brain exhibited higher levels of protein oxidation compared with wild-type mice (Halliwell and Gutteridge, 1990). The results are presented in Figure $16 \mathrm{~A}$, and the data indicate that there are significantly higher levels of protein oxidation in $h s \mathrm{fl}^{-/-}$brain extracts compared with wild-type examined at 5 months of age. Brain extracts from $h s f 1^{+/-}$mice showed intermediate levels of protein oxidation. These results indicate that the cellular proteins in the brain of $h s f 1^{-l-}$ mice exhibit higher than wild-type levels of oxidized proteins.

To investigate whether neuron and astrocyte cultures established in vitro from E18 embryos, or P2 mice also exhibit increased protein oxidation, immunoblot analyses of cells prepared from wild-type or $h s f 1^{-l-}$ mice were performed as above. Interestingly, both neurons and astrocytes derived from $h s f 1^{-1-}$ mice exhibit increased levels of protein oxidation compared with cells prepared from wild-type mice (Fig. 16B). These experiments could not be performed with mature primary oligodendrocytes because of their low numbers in the cultures we could prepare.

\section{Discussion}

Heat shock transcription factors, specifically Hsf1, are unique in that they respond to environmental stressors such as heat shock and oxidative stress to gain transcriptional competence (Wu, 1995; Morimoto, 1998). As such, Hsfs are thought to protect the cells and tissues of the organism against environmental stresses over the organism's lifetime (Zhang et al., 2002). In this report, we show that the absence of the $h s f 1$ gene or the absence of $h s f 1$ in combination with genes for other $h s f s$, namely the $h s f 2$ or $h s f 4$, leads to alterations in the CNS in young adult mice, some of which normally are observed in aged organisms. Although the developmental program of myelination appears normal (Figs. 2, 3, 6), our studies indicate that the young adult of $h s 1^{-1-}$ mice begin to exhibit demyelination associated with astrogliosis. In general, the underlying causes of demyelination are complex and may depend on multiple factors (Berlett and Stadtman, 1997; Franklin et al., 2002). However, oligodendrocytes are the cell types responsible for myelination of axons, and this process continues throughout the life of the organism. Our studies looking at oligodendrocyte progenitors cell division and death during development or in adult $h s f 1^{-/-}$mice did not reveal defects in OPCs division and differentiation in situ. Similarly, we did not detect notable reduction in the number of neurons in $h s f 1^{-/-}$CNS. However, biochemical analyses of $h s f 1^{-/-}$ cells show evidence that these cells have deficiency in degrading ubiquitinated model proteins. This appears to lead to accumulation of ubiquitinated proteins, not only in $h s f 1^{-1-}$ MEFs expressing model proteins, but also in $h s f 1^{-l-}$ astrocytes and brain cell extracts. Neurons appeared to accumulate less ubiquitinated proteins, perhaps because of the fact that Hsfl expression and activity in neurons is less than it is in astrocytes (Bergeron et al., 1996; Taylor et al., 2007). Because astrocytes are critical for maintaining the cellular homeostasis in the brain, such defects in the astrocytes alone could potentially lead to defective oligodendrocyte cell population in $h s f 1^{-/-}$mice. However, if all cell types in $h s f 1^{-/-}$mice exhibit lower than normal levels of ubiquitinproteasome-dependent degradation, such consequences as described here could also be expected. Indeed, defects in ubiquitinproteasome pathway are the underlying cause of many agerelated neurodegenerative diseases. One of the features of neurodegenerative diseases such as Parkinson's disease, Alzheimer's disease, ALS, and prion disorders is the accumulation of ubiquitin-positive inclusion bodies (Price et al., 1998). The ubiquitin-positive inclusions in many neurodegenerative diseases also contain various proteasome components as well as molecular chaperones (Goldberg, 2003). Reports indicate that there is evidence of demyelination in some of the neurodegenerative diseases with ubiquitin-positive inclusion bodies such as $\mathrm{Alz}$ - 
heimer's disease (D. S. Wang et al., 2004). The accumulation of ubiquitin-immunoreactive granular degeneration of myelin has also been observed in the human brain, which has been correlated to agerelated slowing down of motor and cognitive abilities (D. S. Wang et al., 2004). Studies indicate an extensive, whitematter axonal demyelination cause of Alzheimer's pathology, and this may represent the cumulative defects, such as neuronal degeneration, microgliosis, oligodendrocyte injury, and microcirculatory disease, observed in Alzheimer's disease in humans (Bartzokis, 2004; D. S. Wang et al., 2004). Surprisingly, we also detect an increase in protein oxidation in the 5-month-old $h s f 1^{-1-}$ mice and $h s f 1^{-1-}$ primary astrocytes and neurons cultured in vitro. This is a significant finding, because this could cause gradual increase in death of all cell types in the brain. Indeed, we observed significantly higher than wild-type levels of cell death in the spinal cord of 1.5 -year-old $h s f 1^{-1-}$ mice that coincided mainly with astrocytes (Fig. 9) (Whitman and Cotman, 2004). We believe, therefore, that lack of $h s f 1$ gene causes accumulation of defects that normally have been associated with aging CNS.

As far as reduction in which Hsps could potentially be involved in slowing down the ubiquitin-proteasome degradation in $h s f 1^{-1-}$ cells is under investigation in our laboratory. Preliminary results indicate that deficiency in the individual Hsps does not recreate $h s f 1$ deficiency and phenotype; however, a small reduction in multiple Hsps (such as Hsp25 and aB-crystallin) in $h s f 1^{-/-}$cells could be the cause of this reduction in ubiquitin-proteasome function (N. F. Mivechi, unpublished observation). It should be noted that $h s f 1^{-/-}$cells entirely lack the ability to respond to stress and do not accumulate protective Hsps such as Hsp105, -90, -70, -60, -40, -25, aBcrystallin, and Hsp10, and this could be associated with defects observed in $h s f 1^{-l-}$ mice (Zhang et al., 2002). As such, immunoblotting analyses of 8-week-old brain extracts did not reveal any major changes in the steady-state levels of major Hsps (data not shown). In terms of $h s f 1$ potentially controlling the expression of genes other than Hsps to generate phenotype observed here, the microarray analyses of brain at P18 show reduction in Vomeronasal 1 receptor, B1; oxygen-regulated photoreceptor protein 1; WISNF related, matrix associated, actin-dependent regulator of chromatin; and proteases such as Cathepsin $\mathrm{Z}$ as some of the genes whose expression are reduced by twofold or lower in $h s f 1^{-1-}$ brain compared with wild-type mice. $h s f 1^{-/-}$brain at P18 also shows reduced levels (2.3-fold) of neural cell adhesion molecule 1 (NCAM1) compared with wild type. NCAM expression is normally reduced, allowing myelina-
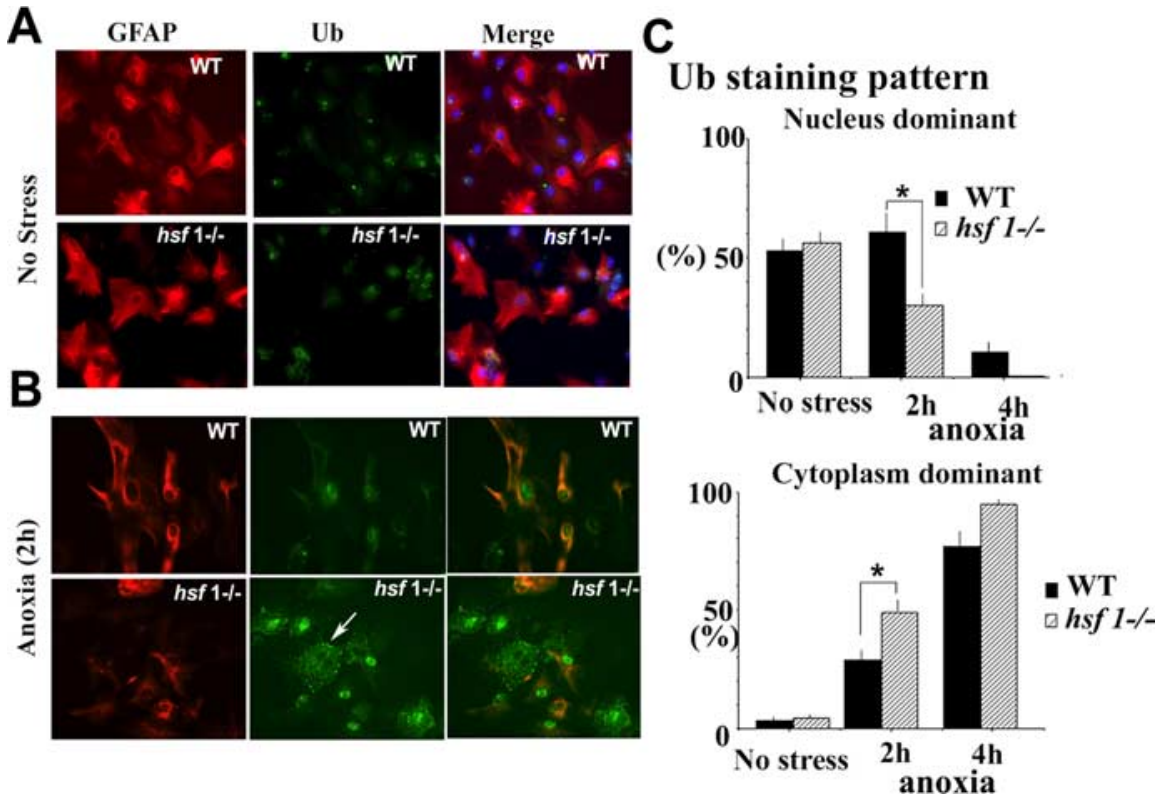

Figure 14. Accumulation of ubiquitinated proteins in the cytoplasm of $h s f 1^{-1-}$ primary astrocytes exposed to anoxia. $A, B$, Immunofluorescent analyses of astrocytes prepared from wild-type or $h s f 1^{-1-}$ mice using antibodies to GFAP (red fluorescent), or to ubiquitin (green fluorescent). Nucleus was stained with DAPI (blue). Astrocytes were cultured from wild-type or $h s f^{-1-}$ it paraformaldehyde and immunostained. Magnification, 400X.C, Quantitiation of cells stained with both GFAP and ubiquitin in staining became more cytoplasmic after stress. Interestingly, $h \mathrm{hf} 1^{-1-}$ astrocytes show significantly more ubiquitin staining in the cytoplasm that appeared punctuated after $2 \mathrm{~h}$ exposure to anoxia ( $\boldsymbol{B}$, arrow), suggesting perhaps ubiquitinated/aggregated

A

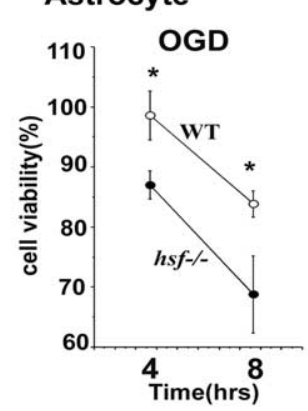

Figure 15. Increased death of $h s f 1^{-1-}$ astrocytes after exposure to ischemia or anoxia. $A$, Astrocytes were cultured at $P 2$ from wild-type or $h s f 1^{-1-}$ littermates. After $7 \mathrm{~d}$ in culture, astrocytes from wild-type or $h s f 1^{-1-}$ mice were exposed to ischemia (OGD), anoxia (0\% oxygen), or GD for 4 or 8 h. Astrocyte viability was determined using MTT assays. ${ }^{*} p<0.05$. B, Primary neurons were cultured from E18 wild-type and $h s f 1^{-1-}$ mice and were exposed to anoxia (0\% oxygen) for $2 \mathrm{~h}$, and viability was determined as in $\boldsymbol{A}$. Error bars indicate SEM. tion to take place (Simons and Trajkovic, 2006). Additional reduction in $h s f 1^{-1-}$ mice may indicate an early deficient process of myelination in these mice. Additional studies will be required to determine which of these genes is regulated by Hsfl.

Although we did not observe excessive inflammatory cell infiltrates in the demyelinated areas in $h s f 1^{-1-}$ brain or spinal cord at the onset of demyelination (data not shown), Hsfl has been shown to regulate the expression of leukemia inhibitory factor (LIF) (Takaki et al., 2006) and other cytokines such as IL-6 (Inouye et al., 2004). Hsf1 apparently represses LIF expression in developing olfactory epithelium, and in the absence of $h s f 1$ gene there is a higher level of LIF, which leads to the death of olfactory 
A

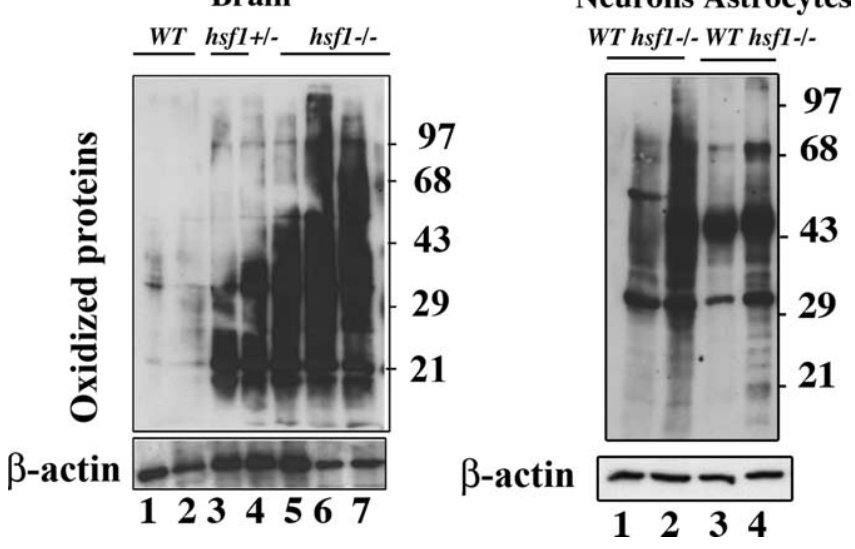

Figure 16. Elevated levels of protein oxidation in $h \mathrm{sf1} 1^{-1-}$ brain. $\boldsymbol{A}$, Immunoblot analyses of brain extracts from wild-type (WT), $h s f 1^{+1-}$, or hsf ${ }^{-1-}$ mice at 5 months of age. Lanes 1 and 2 are brain extracts from wild-type mice; lane 3 is brain extract from $h s 1^{+1-}$ mouse; lanes 4-7 are brain extracts from $h s f 1^{-l-}$ mice. $\boldsymbol{B}$, Untreated primary astrocytes (prepared from P2) and neurons (prepared from E18) cultures prepared from WT, or $h s f 1^{-1-}$ mice. Lanes 1 and 2 are extracts from wild-type and $h s f 1^{-1-}$ neurons, respectively; lanes 3 and 4 are extracts from wild-type and $h s f 1^{-1-}$ astrocytes, respectively. Cell extracts were prepared according to the 0xyBlot 0xidized Protein Detection kit; $30 \mu \mathrm{g}$ of protein was fractionated and oxidized proteins were detected using antibody to DNP (Halliwell and Gutteridge, 1990). Control oxidized molecular weight markers were provided in the kit as a positive control. $\beta$-Actin was used as loading control.

sensory neurons (Takaki et al., 2006). In the CNS, LIF expression is required for the survival of oligodendrocytes (Butzkueven et al., 2002). Whether Hsf1 positively or negatively controls LIF expression in the CNS is unclear; however, $h s f 1$ regulation of LIF expression may contribute to the $h s f 1^{-l-}$ phenotype observed in our studies as well.

Interestingly, hsf1hsf2-deficient mice exhibit a more severe phenotype than mice deficient in $h s f 1$ alone, and these mice exhibit developmental defects in myelination, perhaps defects in oligodendrocyte differentiation or myelin synthesis and assembly. $h s f 1^{-1-} h s f 2^{-1-}$ mice at P18 and at 8 weeks of age showed high levels of dysmyelination and demyelination both at the level of immunostaining for MBP as well as electron microscopic analyses of the cross sections of the spinal cord. However, the numbers of $h s f 1 h s f 2$-deficient mice were not sufficient to perform extensive studies between young versus old mice. These results suggest that both Hsf1 and Hsf2 transcription factors play an overlapping or sequential role in development of CNS. In addition, Hsfs are required to maintain CNS homeostasis and slowing down the events that are normally associated with aging.

\section{References}

Auluck PK, Chan HY, Trojanowski JQ, Lee VM, Bonini NM (2002) Chaperone suppression of alpha-synuclein toxicity in a Drosophila model for Parkinson's disease. Science 295:865-868.

Barral JM, Broadley SA, Schaffar G, Hartl FU (2004) Roles of molecular chaperones in protein misfolding diseases. Semin Cell Dev Biol 15:17-29.

Bartzokis G (2004) Age-related myelin breakdown:a developmental model of cognitive decline and Alzheimer's disease. Neurobiol Aging 25:5-18.

Baumann N, Pham-Dinh D (2001) Biology of oligodendrocytes and myelin in the mammalian central nervous system. Pharmacol Rev 81:871-927.

Bergeron M, Mivechi NF, Giaccia AJ, Giffard RG (1996) Mechanism of heat shock protein 72 induction in primary cultured astrocytes after oxygenglucose deprivation. Neurol Res 18:64-72.

Berlett BS, Stadtman ER (1997) Protein oxidation in aging, disease and oxidative stress. J Biol Chem 272:20313-20316.

Butterfield DA, Howard BJ, LaFontaine MA (2001) Brain oxidative stress in animal models of accelerated aging and the age-related neurodegenerative disorders, Alzheimer's disease and Huntington's disease. Curr Med Chem 8:815-828.

Butzkueven H, Zhang JG, Soilu-Hanninen M, Hochrein H, Chionh F, Shipham KA, Emery B, Turnley AM, Petratos S, Ernst M, Bartlett PF, Kilpatrick TJ (2002) LIF receptor signaling limits immune-mediated demyelination by enhancing oligodendrocyte survival. Nat Med 8:613-619.

Chang Y, Ostling P, Akerfelt M, Trouillet D, Rallu M, Gitton Y, El Fatimy R, Fardeau V, Le Crom S, Morange M, Sistonen L, Mezger V (2006) Role of heat-shock factor 2 in cerebral cortex formation and as a regulator of p35 expression. Genes Dev 20:836-847.

Cummings CJ, Mancini MA, Antalffy B, DeFranco DB, Orr HT, Zoghbi HY (1998) Chaperone suppression of aggregation and altered subcellular proteasome localization imply protein misfolding in SCA1. Nat Genet 19:148-154.

Dantuma NP, Lindsten K, Glas R, Jellne M, Masucci MG (2000) Short-lived green fluorescent proteins for quantifying ubiquitin/proteasomedependent proteolysis in living cells. Nat Biotechnol 18:494-496.

Franklin RJ, Zhao C, Sim FJ (2002) Ageing and CNS remyelination. NeuroReport 13:923-928.

Fujimoto M, Izu H, Seki K, Fukuda K, Nishida T, Yamada S, Kato K, Yonemura S, Inouye S, Nakai A (2004) HSF4 is required for normal cell growth and differentiation during mouse lens development. EMBO J 23:4297-4306

Goldberg AL (2003) Protein degradation and protection against misfolded or damaged proteins. Nature 426:895-899.

Halliwell B, Gutteridge JMC (1990) Role of free radicals and catalytic metal ions in human disesases: an overview. Methods Enzymol 186:1.

Hsu AL, Murphy CT, Kenyon C (2003) Regulation of aging and age-related disease by DAF-16 and heat-shock factor. Science 5622:1142-1145.

$\mathrm{Hu}$ Y, Mivechi NF (2006) Association and regulation of heat shock transcription factor $4 \mathrm{~b}$ with both extracellular signal-regulated kinase mitogen-activated protein kinase and dual-specificity tyrosine phosphatase DUSP26. Mol Cell Biol 8:3282-3294.

Inouye S, Izu H, Takaki E, Suzuki H, Shirai M, Yokota Y, Ichikawa H, Fujimoto M, Nakai A (2004) Impaired IgG production in mice deficient for heat shock transcription factor 1. J Biol Chem 279:38701-38709.

Kazemi-Esfarjani P, Benzer S (2000) Genetic suppression of polyglutamine toxicity in Drosophila. Science 287:1837-1840.

Mariani E, Polidori MC, Cherubini A, Mecocci P (2005) Oxidative stress in brain aging, neurodegenerative and vascular diseases: an overview. J Chromatogr B Analyt Technol Biomed Life Sci 827:65-75.

McMillan DR, Xiao X, Shao L, Graves K, Benjamin IJ (1998) Targeted disruption of heat shock transcription factor 1 abolishes thermotolerance and protection against heat-inducible apoptosis. J Biol Chem 273:7523-7528.

Min J, Zhang Y, Moskophidis D, Mivechi NF (2004) Unique contribution of heat shock transcription factor 4 in ocular lens development and fiber cell differentiation. Genesis 40:205-217.

Morimoto RI (1998) Regulation of the heat shock transcriptional response: cross talk between a family of heat shock factors, molecular chaperones, and negative regulators. Genes Dev 12:3788-3796.

Muchowski PJ, Wacker JL (2005) Modulation of neurodegeneration by molecular chaperones. Nat Rev Neurosci 6:11-22.

Price DL, Sisodia SS, Borchelt DR (1998) Genetic neurodegenerative diseases: the human illness and transgenic models. Science 282:1079-1083.

Rorden C, Brett M (2002) Stereotaxic display of brain lesions. Behav Neurol 12:191-200.

Santos SD, Saraiva MJ (2004) Enlarged ventricles, astrogliosis and neurodegeneration in heat shock factor 1 null mouse brain. Neuroscience 126:657-663.

Schaffar G, Breuer P, Boteva R, Behrends C, Tzvetkov N, Strippel N, Sakahira H, Siegers K, Hayer-Hartl M, Hartl FU (2004) Cellular toxicity of polyglutamine expansion proteins: mechanism of transcription factor deactivation. Mol Cell 15:95-105.

Scherer SS (1997) Molecular genetics of demyelination: new wrinkles on an old membrane. Neuron 18:13-16.

Sereda M, Griffiths I, Puhlhofer A, Stewart H, Rossner MJ, Zimmerman F, Magyar JP, Schneider A, Hund E, Meinck HM, Suter U, Nave KA (1996) A transgenic rat model of Charcot-Marie-Tooth disease. Neuron 1:1049-1060.

Simons M, Trajkovic K (2006) Neuron-glia communication in the control 
of oligodendrocyte function and myelin biogenesis. J Neurosci 119:4381-4389.

Soti C, Csermely P (2002) Chaperones and aging: role in neurodegeneration and in other civilizational diseases. Neurochem Int 41:383-389.

Stacchiotti A, Rezzani R, Rodella L, Tiberio L, Schiaffonati L, Bianchi R (1999) Cell-specific expression of heat shock transcription factors 1 and 2 in unstressed rat spinal cord. Neurosci Lett 268:73-76.

Takaki E, Fujimoto M, Sugahara K, Nakahari T, Yonemura S, Tanaka Y, Hayashida N, Inouye S, Takemoto T, Yamashita H, Nakai A (2006) Maintenance of olfactory neurogenesis requires HSF1, a major heat shock transcription factor in mice. J Biol Chem 281:4931-4937.

Taylor D, De Koninck P, Minotti S, Durham HD (2007) Manipulation of protein kinases reveals different mechanisms for up regulation of heat shock proteins in motor neurons and non-neuronal cells. Mol Cell Neurosci 34:20-33.

Tu N, Hu Y, Mivechi NF (2006) Heat shock transcription factor (Hsf)-4b recruits Brg1 during the $G_{1}$ phase of the cell cycle and regulates the expression of heat shock proteins. J Cell Biochem 98:1528-1542.

Walsh D, Li Z, Wu Y, Nagata K (1997) Heat shock and the role of the HSPs during neural plate induction in early mammalian CNS and brain development. Cell Mol Life Sci 53:198-211.
Wang DS, Bennett DA, Mufson EJ, Mattila P, Cochran E, Dickson DW (2004) Contribution of changes in ubiquitin and myelin basic protein to age-related cognitive decline. Neurosci Res 48:93-100.

Wang G, Zhang J, Moskophidis D, Mivechi NF (2003) Targeted disruption of the Hsf2 gene results in increased embryonic lethality, neuronal defects, and reduced spermatogenesis. Genesis 36:48-61.

Wang G, Ying Z, Jin X, Tu N, Zhang Y, Phillips M, Moskophidis D, Mivechi NF (2004) Essential requirement for both $h s f 1$ and $h s f 2$ transcriptional activity in spermatogenesis and male fertility. Genesis 38:66-80.

Whitman GT, Cotman CW (2004) Oligodendrocyte degeneration in AD. Neurobiol Aging 25:33-36.

Wu C (1995) Heat shock transcription factors: structure and regulation. Annu Rev Cell Dev Biol 11:441-469.

Xiao X, Zuo X, Davis AA, McMillan DR, Curry BB, Richardson JA, Benjamin IJ (1999) HSF1 is required for extra-embryonic development, postnatal growth and protection during inflammatory responses in mice. EMBO J 18:5943-5952.

Zhang Y, Huang L, Zhang J, Moskophidis D, Mivechi NF (2002) Targeted disruption of hsfl leads to lack of thermotolerance and defines tissuespecific regulation for stress-inducible Hsps. J Cell Biochem 86:376-393. 